\title{
A long-term study of aerosol-cloud interactions and their radiative effect at the Southern Great Plains using ground-based measurements
}

\author{
Elisa T. Sena ${ }^{1,2}$, Allison McComiskey ${ }^{3}$, and Graham Feingold ${ }^{2}$ \\ ${ }^{1}$ Institute of Physics, University of São Paulo, São Paulo, Brazil \\ ${ }^{2}$ NOAA Chemical Sciences Division, Boulder, CO, USA \\ ${ }^{3}$ NOAA Global Monitoring Division, Boulder, CO, USA \\ Correspondence to: Elisa T. Sena (elisa.sena@ noaa.gov) \\ Received: 30 March 2016 - Published in Atmos. Chem. Phys. Discuss.: 4 April 2016 \\ Revised: 24 August 2016 - Accepted: 25 August 2016 - Published: 13 September 2016
}

\begin{abstract}
Empirical estimates of the microphysical response of cloud droplet size distribution to aerosol perturbations are commonly used to constrain aerosol-cloud interactions in climate models. Instead of empirical microphysical estimates, here macroscopic variables are analyzed to address the influence of aerosol particles and meteorological descriptors on instantaneous cloud albedo and the radiative effect of shallow liquid water clouds. Long-term ground-based measurements from the Atmospheric Radiation Measurement (ARM) program over the Southern Great Plains are used. A broad statistical analysis was performed on 14 years of coincident measurements of low clouds, aerosol, and meteorological properties. Two cases representing conflicting results regarding the relationship between the aerosol and the cloud radiative effect were selected and studied in greater detail. Microphysical estimates are shown to be very uncertain and to depend strongly on the methodology, retrieval technique and averaging scale. For this continental site, the results indicate that the influence of the aerosol on the shallow cloud radiative effect and albedo is weak and that macroscopic cloud properties and dynamics play a much larger role in determining the instantaneous cloud radiative effect compared to microphysical effects. On a daily basis, aerosol shows no correlation with cloud radiative properties (correlation $=-0.01 \pm 0.03)$, whereas the liquid water path shows a clear signal (correlation $=0.56 \pm 0.02$ ).
\end{abstract}

\section{Introduction}

Clouds are major contributors to global reflectivity (Trenberth et al., 2009). Thus, changes in cloud albedo, coverage and lifetime have a large impact on the Earth's radiation budget. Additionally, changes in precipitation patterns may have a large impact on agriculture, the environment and human well-being.

The influence of aerosol on clouds and its contribution to cloud radiative forcing has become a theme of much debate in the scientific community (Boucher et al., 2013). The processes involved in cloud development, aerosol and cloud lifecycles, and cloud radiative responses are complex and not well represented in global climate models (GCMs). Microphysical responses associated with aerosol effects on cloud albedo tend to be described as a sequence of more aerosol resulting in more cloud condensation nuclei $(\mathrm{CCN})$, and all else equal, smaller cloud drops and a more reflective cloud (Twomey, 1974, 1977). However, aerosol, dynamics and macroscopic cloud properties are interconnected, and may result in mutually compensating effects and adjustments that are not fully understood (Stevens and Feingold, 2009). For example, smaller drops may suppress precipitation and increase cloudiness (Albrecht, 1989) or, by enhancing entrainment and evaporation, decrease cloud amount (Wang et al., 2003; Ackerman et al., 2004; Small et al., 2009). Absorbing aerosol could also modify the atmospheric temperature profile and stability, and reduce cloud amount via the semidirect effect (e.g., Koren et al., 2008; Huang et al., 2009). 
Therefore, cloud microphysical variations do not necessarily manifest as changes in cloud albedo and radiative forcing (Han et al., 1998). The influence of meteorological drivers and thermodynamic conditions (e.g., atmospheric stability and humidity) on aerosol-cloud interaction assessments is increasingly being brought into focus (e.g., Kaufman, et al., 2005; Engström and Eckman, 2010; Koren et al., 2012; Chen et al., 2014, 2015). However, untangling the cloud microphysical effects from dynamics and isolating their contributions to the radiative balance still remains a big challenge. Direct, independent and collocated measurements of each pertinent variable are required for understanding the impact of the anthropogenic aerosol on the cloud radiative effect (McComiskey and Feingold, 2012). Evidence for anthropogenic aerosol influence on cloud droplet number concentration and effective radius is commonly noted in in situ airborne measurements (e.g., Warner and Twomey, 1967; Eagan et al., 1974; Ackerman et al., 2000; Twohy et al., 2005). Over the past 2 decades, satellite remote sensing has been widely used to study aerosol-cloud interactions over large areas (e.g., Nakajima et al., 2001; Bréon et al., 2002; Quaas et al., 2008; Costantino and Bréon, 2010), usually showing weaker responses than airborne-based studies. Space-borne assessments of aerosol-cloud interactions face many challenges, such as cloud contamination of the aerosol measurement, aerosol humidification effects near clouds, and the difficulty in obtaining collocated aerosol and cloud measurements. Different observational scales and platforms result in large variations in the aerosol-cloud interaction assessments (McComiskey and Feingold, 2012).

The Department of Energy's (DOE) Atmospheric Radiation Measurement (ARM) Program continuously operates permanent and mobile facilities that allow monitoring and study of the atmosphere at different sites. The unrivaled combination of in situ and ground-based remote sensing instruments provides collocated and simultaneous measurements of different cloud, aerosol and meteorological properties. ARM ground-based instrumentation has been previously used to study aerosol-cloud interactions at several sites around the world (e.g., Feingold et al., 2003; Kim et al., 2003, 2008; Garrett et al., 2004; McComiskey et al., 2009). These studies focused on the microphysical aspect of aerosol-cloud interaction, analyzing a handful, to months, to up to 3 years of measurements. The ARM Program has been operating at the Southern Great Plains (SGP), Oklahoma, for more than 2 decades (since 1992). The availability of such a large and comprehensive data set provides an excellent opportunity to pursue a long-term study of the effects of aerosol and meteorology on clouds.

In this work, 14 years of ARM ground-based measurements at the SGP were analyzed to investigate the effects of aerosol and meteorological drivers (such as capping inversion strength, surface-boundary layer coupling and turbulence) on clouds. Instead of quantifying the usual metrics for microphysical response to an aerosol perturbation, we fo- cus on the analysis of aerosol associations with cloud macroscopic variables and radiative properties. These quantities are more closely related to the cloud radiative effect and therefore represent a pragmatic pathway towards quantification.

The structure of the paper is as follows: Sect. 2 describes the methodology. A climatology of low, warm, nonprecipitating clouds at the SGP is then presented (Sect. 3.1). Some simple approximations are used to illustrate the theoretical basis behind the data analysis (Sect. 3.2). A broad statistical analysis of more than a decade of coincident groundbased measurements of cloud radiative properties and their relationship with meteorology and aerosol concentration is shown (Sect. 3.3). Two interesting cases are selected and studied more deeply to improve our understanding of the problem (Sect. 3.4). Common features observed in the case studies are further explored (Sect. 3.5). We summarize our results in Sect. 4.

\section{Methodology}

Coincident ground-based remote sensing and in situ measurements of clouds, aerosol and meteorological properties from Atmospheric Radiation Measurement (ARM) deployments at the SGP, central facility, near Lamont, Oklahoma $\left(36.61^{\circ} \mathrm{N}, 97.48^{\circ} \mathrm{W}\right)$, were used. The period of data analysis ranges from 1997 to 2010 and includes all available data that present coincident measurements of the variables considered, subject to the restrictions described below.

The Active Remotely Sensed Cloud Locations (ARSCL) Value-Added Product (Clothiaux et al., 2000) was used to select low, warm, non-precipitating clouds from the full 14 years of data. This product combines measurements from a Ka-band cloud radar ( $35 \mathrm{GHz}$ or $8.6 \mathrm{~mm}$ wavelength), a ceilometer at a wavelength of $910 \mathrm{~nm}$ and a micropulse lidar (MPL) at $532 \mathrm{~nm}$ to provide, among other variables, best estimates of cloud boundaries at $10 \mathrm{~s}$ resolution. To avoid ice, the cloud base height $h_{\mathrm{CB}}$ was limited between 300 and $2000 \mathrm{~m}$ and the cloud top $h_{\mathrm{CT}}$ was limited to $3000 \mathrm{~m}$. Cases that presented more than one layer of cloud were excluded from the analysis. Drizzle was mostly avoided by limiting the maximum column radar reflectivity $(Z)$ to less than $-17 \mathrm{dBZ}$ (Frisch et al., 1995).

Surface broadband shortwave radiative fluxes were used to obtain cloud optical depth $\tau_{\mathrm{c}}$, (a parameter closely related to cloud albedo, $A_{\mathrm{c}}$ ), cloud fraction $f_{\mathrm{c}}$, and the instantaneous relative cloud radiative effect, using the Radiative Flux Analysis (RFA) evaluation product (Barnard and Long, 2004; Long and Ackerman, 2000; Long and Shi, 2006; Long et al., 2006). Overcast conditions $\left(f_{\mathrm{c}}>0.9\right.$ on the scale of hundreds of meters) and solar zenith angle smaller than $80^{\circ}$ are required to retrieve $\tau_{\mathrm{c}}$. Parameters $A_{\mathrm{c}}$ and $f_{\mathrm{c}}$ were simultaneously retrieved using piecewise polynomial fits to functions of shortwave upward and downward radiation fluxes (Liu et al., 2011; Xie and Liu, 2013). rCRE, a non-dimensional mea- 
sure of instantaneous cloud radiative forcing, or cloud radiative effect (Betts and Viterbo, 2005) is defined as

$\mathrm{rCRE}=1-\frac{F_{\mathrm{all}}^{\mathrm{dn}}}{F_{\mathrm{clr}}^{\mathrm{dn}}}$,

where $F_{\text {all }}^{\text {dn }}$ and $F_{\text {clr }}^{\text {dn }}$ are the broadband all-sky and clear-sky surface downwelling shortwave radiative fluxes (from 0.3 to $3.0 \mu \mathrm{m}$ ), respectively. The use of downwelling fluxes as opposed to net fluxes minimizes the effects of surface albedo on rCRE (Vavrus, 2006).

The aerosol index $A_{\mathrm{i}}$ was calculated from the surface scattering coefficient at $550 \mathrm{~nm}\left(\sigma_{550 \mathrm{~nm}}\right)$ multiplied by the Ångström exponent $(\AA)$ and used as a proxy for CCN concentration (Nakajima et al., 2001)

$A_{\mathrm{i}}=\sigma_{550 \mathrm{~nm}} \AA$,

where $\AA$ and $\sigma_{550 \mathrm{~nm}}$ were measured by a 3-channel nephelometer (at 450,550 and $700 \mathrm{~nm}$ ) at $1 \mathrm{~min}$ resolution (Sheridan et al., 2001). An impactor at the inlet connected to the nephelometer alternates the cut size from 1 to $10 \mu \mathrm{m} \mathrm{ev-}$ ery $6 \mathrm{~min}$. Only measurements obtained at the $1 \mu \mathrm{m}$ size cut were selected. The data were interpolated to 1 min resolution, when necessary. The decision to use surface measurements is not only pragmatic (they are available) but also supported by the result that at SGP the relationship between surface aerosol measurements and cloud level aerosol measurements has been shown to be uncorrelated with the degree of boundary layer vertical mixing (Delle Monache et al., 2004). Their work shows that, at SGP, extensive and intensive aerosol properties measured at the surface and within the atmospheric boundary layer are well-correlated. Therefore, surface-based measurements of aerosol properties are representative of the air within the atmospheric boundary layer. They also show that this finding does not depend on the mixing state of the atmosphere. Another proxy for CCN was also used and showed similar results to those obtained using $A_{\mathrm{i}}$ (see Fig. S1 in the Supplement). Liquid water path (LWP) retrievals from a 2-channel $(23.8$ and $31.4 \mathrm{GHz})$ microwave radiometer (MWR) at $20 \mathrm{~s}$ resolution (Turner et al., 2007a) were used. Two different LWP ranges were selected. In the first part of this work (Sect. 3.3), our goal is to understand how several different properties impact rCRE. For this part of the study, the LWP is limited between 30 and $250 \mathrm{~g} \mathrm{~m}^{-2}$, allowing us to include cloud types ranging from low liquid water clouds (Vogelmann et al., 2012; Turner et al., 2007b), some of which are likely broken, to thicker, possibly drizzling clouds. The lower limit was set taking into account the large uncertainty in the MWR retrieval for low LWP. For the remaining analysis LWP was further restricted from 50 to $150 \mathrm{~g} \mathrm{~m}^{-2}$. The larger restriction to the upper range was applied to minimize contributions from precipitating events. The increased lower limit avoids very thin or broken clouds where the uncertainty in measuring LWP is high (Turner et al., 2007b).
Turbulence, via its influence on supersaturation, plays an important role in determining the number concentration of aerosol particles that are activated to become cloud droplets (e.g., Twomey, 1959; Feingold et al., 2003). The vertical component of the turbulent kinetic energy provides an estimate of the strength of the turbulent fluxes acting at cloud base. Doppler radar vertical velocities were used to calculate a proxy for turbulence given by $w^{\prime 2}=\left[w-w_{0}\right]^{2}$, where $w$ is the Doppler radar vertical velocity at the cloud base, and $w_{0}$ is the average vertical velocity at the cloud base centered \pm 30 min around each measurement.

The decoupling index $D_{\mathrm{i}}$ is an indicator of how wellmixed the atmosphere is, and therefore how well groundbased measurements of conserved variables and aerosol properties represent the same at cloud base:

$D_{\mathrm{i}}=\frac{h_{\mathrm{CB}}-\mathrm{LCL}}{h_{\mathrm{CB}}}$,

where the lifting condensation level (LCL) is calculated using ground-based meteorological measurements of surface pressure, vapor mixing ratio and temperature. As the $D_{i}$ retrieval depends on $h_{\mathrm{CB}}$ it can only be calculated in the presence of a cloud. This means that $D_{\mathrm{i}}$ does not necessarily reflect the mean mixing state, unless $f_{\mathrm{c}}$ is high. In brokencloud scenes, a cloud element may be well coupled, whereas the average for the entire boundary layer may be poorly coupled. This should be kept in mind in subsequent discussion.

The lower tropospheric stability (LTS), given by the difference between potential temperatures at $700 \mathrm{hPa}$ and at the surface, was also analyzed. This variable is related to the strength of the capping inversion. Studies show that LTS correlates well with the $f_{\mathrm{c}}$ of low stratiform clouds (Klein and Hartmann, 1993; Chen et al., 2014). The potential temperatures were obtained from the merged sounding value-added product (Troyan, 2012), version 1. This product combines radiosondes, MWRs, surface measurements and the European Centre for Medium Range Weather Forecast (ECMWF) model output to provide several relevant meteorological parameters at $1 \mathrm{~min}$ resolution, at 266 pressure levels, up to $20 \mathrm{~km}$.

A summary of the instruments, the temporal resolution in the original data set, measurements and retrievals used in this work is shown in Table 1. All of the relevant variables were averaged (or interpolated, in case of $A_{\mathrm{i}}$ ) to $1 \mathrm{~min}$ resolution for the analyses presented here.

\section{Results}

\subsection{Database characterization}

A statistical analysis of the data set used in this study is performed. Relative frequency histograms show the distribution of some of the key properties that satisfy the selection criteria explained in the previous section (Fig. 1). Red bars represent 
Table 1. List of the measurements, retrievals and ARM instruments at the Southern Great Plains used in this study.

\begin{tabular}{lll}
\hline Instrument & Resolution in the original data set & Measurement/retrieval \\
\hline Millimeter wavelength cloud radar (MMCR) & $10 \mathrm{~s}$ & Column maximum reflectivity $\left(Z_{\mathrm{max}}\right)$ \\
Ceilometer/micropulse lidar (MPL) & $10 \mathrm{~s}$ & Cloud base height $\left(h_{\mathrm{CB}}\right)$ \\
MMCR/MPL & $10 \mathrm{~s}$ & Cloud top height $\left(h_{\mathrm{CT}}\right)$ \\
MMCR + ceilometer & $10 \mathrm{~s}$ & $\begin{array}{l}\text { Doppler vertical velocity at } h_{\mathrm{CB}}(w) \\
\text { Microwave radiometer (MWR) }\end{array}$ \\
\hline Broadband radiometers & $20 \mathrm{~s}$ & Liquid water path $(\mathrm{LWP})$ \\
& $1 \mathrm{~min}$ & Relative cloud radiative effect (rCRE) \\
& & Cloud optical depth $\left(\tau_{\mathrm{c}}\right)$ \\
& & Cloud fraction $\left(f_{\mathrm{c}}\right)$ \\
\hline Nephelometer & $1 \mathrm{~min}$ & Cloud albedo $\left(A_{\mathrm{c}}\right)$ \\
\hline Meteorological station (MET) & & Scattering at 550 nm $\left(\sigma_{550 \mathrm{~nm}}\right)$ \\
Radiosondes + MET + MWR + models & $1 \mathrm{~min}$ & Angström exponent $(\AA)$ \\
\hline
\end{tabular}

the distribution obtained when LWP is limited between 30 and $250 \mathrm{~g} \mathrm{~m}^{-2}$; the blue bars are obtained by limiting LWP between 50 and $150 \mathrm{~g} \mathrm{~m}^{-2}$. The mean (dot), median (cross) and standard deviation (vertical lines) are shown above each distribution. The data set represents about 66000 valid observations for the first criterion (red) and about 39000 for the second criterion (blue). Due to the long duration of this study period, these distributions can be regarded as representative of low-level, warm, non-precipitating clouds at the SGP for the selection criteria stated above.

Figure 1a shows that the data are dominated by clouds with lower LWP, with the number of observations decreasing as LWP increases. The more restrictive LWP limit (blue bars) shows a higher relative frequency than the less restrictive limit (red bars), due to the smaller number of observations. The non-cloud properties are barely affected by changing the LWP limits. For $A_{\mathrm{i}}, D_{\mathrm{i}}$, LTS and $w^{\prime 2}$ (Fig. 1i-1) the red and blue distributions are essentially the same. On the other hand, the distributions of most of the cloud properties are modified depending on the LWP limit considered. $A_{\mathrm{c}}$, cloud thickness, $\tau_{\mathrm{c}}, \mathrm{rCRE}$ and $f_{\mathrm{c}}$ show a narrower distribution when the LWP range is restricted (Fig. 1c-f), indicating that these variables are closely related to LWP (Turner el al., 2007b).

Due to our selection criteria (low, warm, non-precipitating clouds), most of the data represent stratiform clouds, characterized by high $f_{\mathrm{c}}$. Figure $1 \mathrm{~b}$ shows that about $92 \%$ of the observations were acquired in overcast conditions $\left(f_{\mathrm{c}}\right.$ greater than 0.9). The number of broken-cloud observations $\left(f_{\mathrm{c}}<0.9\right)$ is about 6800 and 3300 for the less and more restrictive LWP ranges, respectively. The fraction of data points with $f_{\mathrm{c}}>0.99$ is $79 \%$, for LWP between 50 and $150 \mathrm{~g} \mathrm{~m}^{-2}$ and $75 \%$ for LWP between 30 and $250 \mathrm{~g} \mathrm{~m}^{-2}$.

To a good approximation, rCRE is directly proportional to both $A_{\mathrm{c}}$ and $f_{\mathrm{c}}$ (Xie and Liu, 2013):

$\mathrm{rCRE} \sim f_{\mathrm{c}} A_{\mathrm{c}}$
As most of the observations were obtained in overcast conditions (Fig. 1b), rCRE in this study is mostly determined by $A_{\mathrm{c}}$, and therefore the shapes of the distributions of $\mathrm{rCRE}$ and $A_{\mathrm{c}}$ (Fig. $1 \mathrm{c}-\mathrm{d}$ ) are very similar (slightly negatively skewed). Due to the polynomial criterion used to calculate $A_{\mathrm{c}}$, about $0.5 \%$ of the observations resulted in $A_{\mathrm{c}}=0$. The median values obtained for rCRE, $A_{\mathrm{c}}$ and $\tau_{\mathrm{c}}$ (Fig. 1c-e) were about $0.68,0.62$ and 17, respectively, for the more restrictive LWP range, and about 2 to $3 \%$ smaller when the LWP restriction was relaxed.

As expected, the $A_{\mathrm{i}}$ distribution (Fig. 1i) is positively skewed indicating the predominance of clean cases (low $A_{\mathrm{i}}$ ) over polluted cases. The distribution of the turbulence proxy $\left(w^{\prime 2}\right)$ peaks at 0 and rapidly decreases as $w^{\prime 2}$ increases. This is due to the small number of cumulus observations in the database, which are usually associated with higher turbulent fluxes. For about one-third of the observations, $w^{\prime 2}$ is greater than 0.1 .

Most of the selected clouds can be classified as thin clouds (Fig. 1f). About $54 \%$ of the observations correspond to clouds thinner than $500 \mathrm{~m}$, with cloud thickness peaking at about $300 \mathrm{~m}$. Almost $70 \%$ of the cases correspond to clouds with $h_{\mathrm{CB}}$ lower than $1 \mathrm{~km}$, and for more than $82 \%$ of the cases, $h_{\mathrm{CT}}$ is lower than $2 \mathrm{~km}$.

By definition (Eq. 3) a value of $D_{\mathrm{i}}=0$ represents a wellmixed boundary layer, whereas values greater than 0 represent progressively more decoupled boundary layers and therefore progressively weaker vertical mixing. The median of the $D_{\mathrm{i}}$ distribution (Fig. $1 \mathrm{k}$ ) is about 0.37 , and about $31 \%$ of the observations show significant decoupling with $D_{\mathrm{i}}$ larger than 0.5 . The few cases of negative $D_{\mathrm{i}}$ shown in this distribution are most likely attributed to incorrect retrievals of the $h_{\mathrm{CB}}$. The LTS distribution (Fig. 11) is roughly symmetrical and varies between 9 and $20 \mathrm{~K}$, within 1 standard deviation. These LTS values are smaller than a previously 

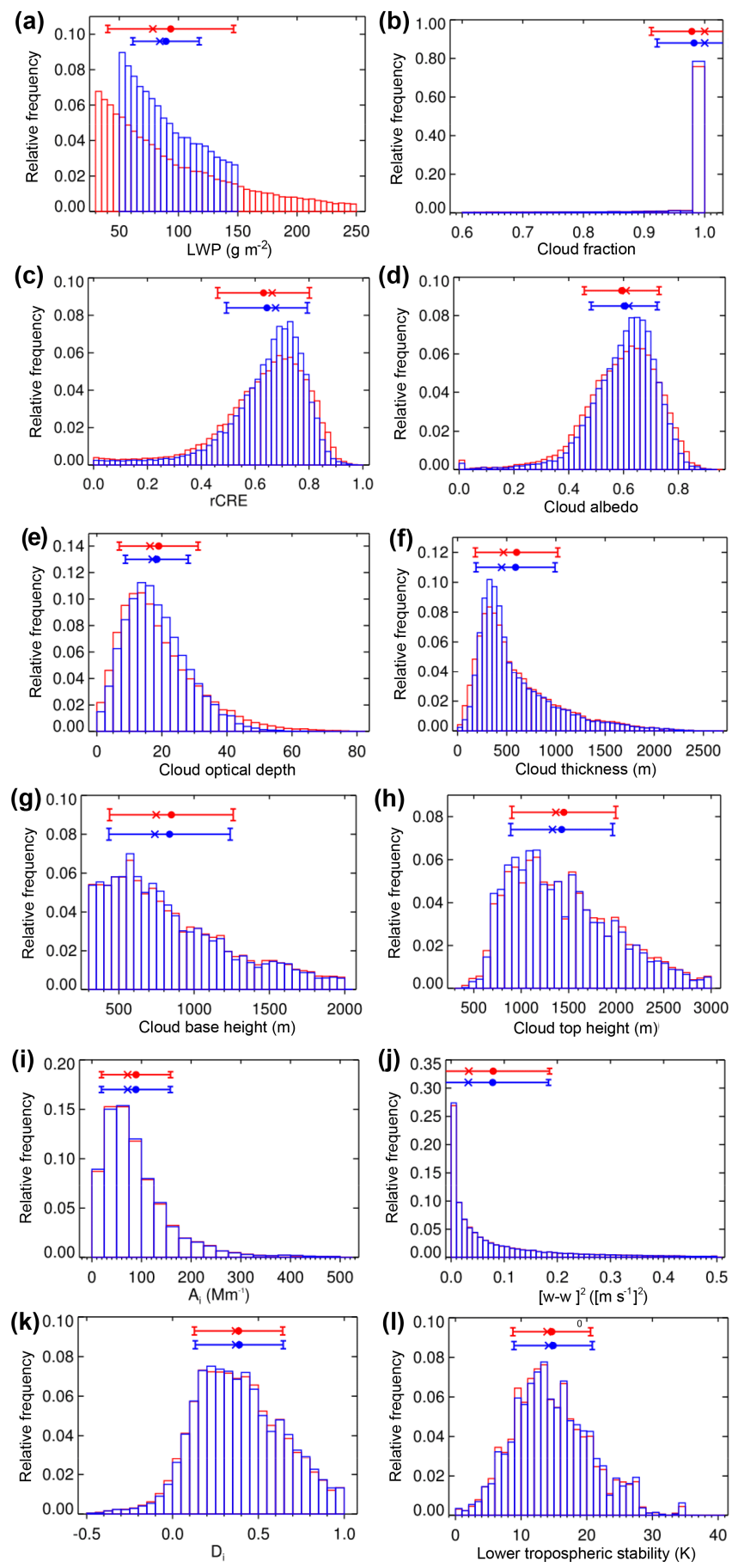

Figure 1. Statistical distributions of (a) liquid water path (LWP), (b) cloud fraction $\left(f_{\mathrm{c}}\right)$, (c) rCRE, (d) cloud albedo $\left(A_{\mathrm{c}}\right)$, (e) cloud optical depth $\left(\tau_{\mathrm{c}}\right)$, (f) cloud thickness, $(\mathrm{g})$ cloud base height $\left(h_{\mathrm{CB}}\right)$, (h) cloud top height $\left(h_{\mathrm{CT}}\right)$, (i) aerosol index $\left(A_{\mathrm{i}}\right),(\mathbf{j}) w^{\prime 2}=[w-$ $\left.w_{0}\right]^{2},(\mathbf{k})$ decoupling index $\left(D_{\mathrm{i}}\right)$ and (l) lower tropospheric stability (LTS). published long-term evaluation (2001-2010) that reported a mean value of $20.81 \mathrm{~K}$ for stratiform clouds at SGP (Ghate et al., 2015), based on 83 radiosonde soundings obtained between 2001 and 2010, for both, nighttime and daytime. A low bias in the LTS from the merged sonde product can be expected because of the inherent smoothing of the merged soundings used in this work.

Notwithstanding the important role of $f_{\mathrm{c}}$ in cloud radiative effect (Eq. 4), the predominance of high $f_{\mathrm{c}}$ in this data set shifts our attention in the following analysis to the relationships amongst rCRE, $A_{\mathrm{c}}, \tau_{\mathrm{c}}$, LWP and $A_{\mathrm{i}}$.

\subsection{Theoretical basis}

For high $f_{\mathrm{c}}$ conditions, cloud liquid water is an important driver of variability in cloud radiative effect because it is so tightly correlated with $\tau_{\mathrm{c}}$ and $A_{\mathrm{c}}$ (e.g., Han et al., 1998; Kim et al., 2003; Chen et al., 2014). Thus, we are particularly interested in the relationship between rCRE and LWP and, by contrast, the relationship between rCRE and aerosol. To give us some insight into the expected behavior of this function, a simple theoretical relation is derived.

The rCRE (Eq. 1), can be expressed as

$\mathrm{rCRE}=1-T$,

where $T$ is the total cloud transmissivity.

Considering conservative cloud scattering (i.e., no absorption), $T$ is obtained using a two-stream radiative transfer approximation (Bohren, 1987) given by

$T=\frac{2 \cos \theta_{0}}{2+\frac{(1-g) \tau_{\mathrm{c}}}{\cos \theta_{0}}}$,

where $g$ represents the asymmetry parameter of the cloud droplets and $\theta_{0}$ is the solar zenith angle. This same twostream approximation yields

$A_{\mathrm{c}}=\frac{\frac{(1-g) \tau_{\mathrm{c}}}{\cos \theta_{0}}}{2+\frac{(1-g) \tau_{\mathrm{c}}}{\cos \theta_{0}}}$.

Replacing $T$ (Eq. 6) in Eq. (5) and performing some algebraic manipulations, the rCRE can be expressed as a function of $\tau_{\mathrm{c}}$ :

$\mathrm{rCRE}=\left[1+\frac{2 \cos \theta_{0}}{(1-g) \tau_{\mathrm{c}}}\right]^{-1}$.

Equation (8) shows that, for fixed illumination angle and cloud scattering geometry, rCRE increases with $\tau_{\mathrm{c}}$.

In the adiabatic regime, $\tau_{\mathrm{c}}$ relates to cloud droplet concentration $\left(N_{\mathrm{d}}\right)$ and LWP through (Boers and Mitchell, 1994)

$\tau_{\mathrm{c}}=c(T, p) N_{\mathrm{d}}^{\frac{1}{3}} \operatorname{LWP}^{\frac{5}{6}}$,

where $c(T, p)$ is a known function of temperature $T$ and pressure $p$. According to Eq. (9), the LWP contribution to 

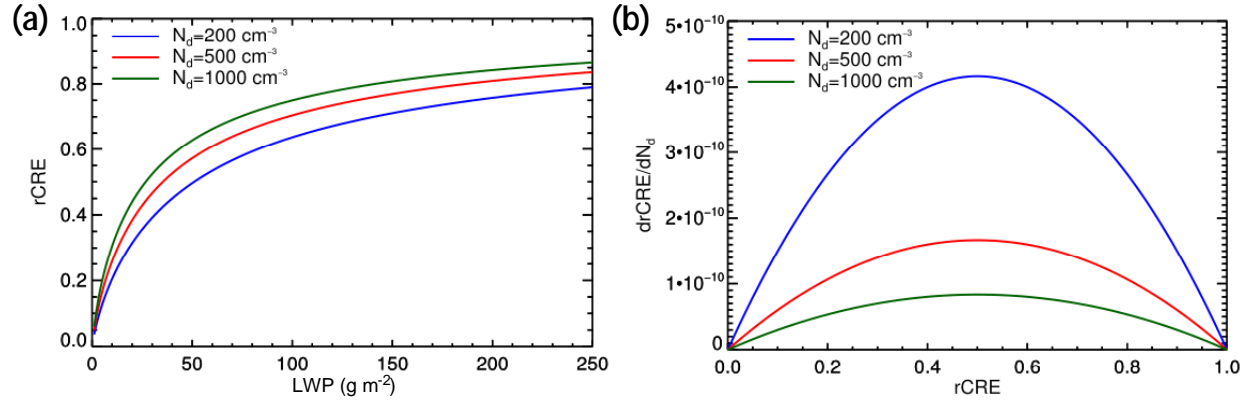

Figure 2. Theoretical approximations of (a) rCRE as a function of LWP, and (b) cloud radiative susceptibility to $N_{\mathrm{d}}$ as a function of rCRE for different droplet concentrations: $N_{\mathrm{d}}=200 \mathrm{~cm}^{-3}$ (blue), $N_{\mathrm{d}}=500 \mathrm{~cm}^{-3}$ (red) and $N_{\mathrm{d}}=1000 \mathrm{~cm}^{-3}$ (green).

$\tau_{\mathrm{c}}$ is, in a relative sense, 2.5 times larger than that of $N_{\mathrm{d}}$. The same can be shown to be true for sub-adiabatic clouds (Boers and Mitchell, 1994). Note that in presenting these equations with respect to $N_{\mathrm{d}}$ we inherently assume a proportionality between $N_{\mathrm{d}}$ and aerosol concentration $N_{\mathrm{a}}$ (or proxy such as $A_{\mathrm{i}}$ ). If $\tau_{\mathrm{c}}$ were to be cast in terms of $N_{\mathrm{a}}$, the power-law dependence of $\tau_{\mathrm{c}}$ on $N_{\mathrm{a}}$ would be less than one-third. Because of the uncertainty in the relationship between $N_{\mathrm{d}}$ and $N_{\mathrm{a}}$, we use $N_{\mathrm{d}}$ to simplify the theoretical arguments.

$\tau_{\mathrm{c}}$ (and therefore $A_{\mathrm{c}}$ ) thus subsumes both the amount of condensed water (a macroscale property) and drops (or aerosol) concentration (a microphysical property). Thus, the extent to which the rCRE dependence on LWP differs for different aerosol concentrations is an expression of the importance of the aerosol in driving rCRE.

Using Eqs. (8) and (9), rCRE can be expressed as a function of LWP and $N_{\mathrm{d}}$. The radiative susceptibility of a cloud to changes in $N_{\mathrm{d}}$ is given by

$$
\frac{\mathrm{drCRE}}{\mathrm{d} N_{\mathrm{d}}}=\left.\frac{\mathrm{rCRE}(1-\mathrm{rCRE})}{3 N_{\mathrm{d}}}\right|_{\mathrm{LWP}} .
$$

Figure 2 shows examples of the theoretical relationships between rCRE and LWP, and between cloud radiative susceptibility and rCRE for different $N_{\mathrm{d}}: 200 \mathrm{~cm}^{-3}$ (blue), $500 \mathrm{~cm}^{-3}$ (red) and $1000 \mathrm{~cm}^{-3}$ (green). The mean solar zenith angle $\left(\theta_{0}\right)$ observed at SGP $\left(\theta_{0}=45^{\circ}\right)$ was used, and we assumed $g=0.86, T=300 \mathrm{~K}$ and $p=1000 \mathrm{mb}$.

Figure 2a shows that for lower LWP values rCRE increases rapidly with increasing LWP. The rate of increase decreases with a progressive increase in LWP until the curve begins to saturate. In this example, the saturation begins for rCRE between around 0.7 to 0.8 . Complete saturation does not occur at $\mathrm{rCRE}=1$ due to the diffuse component of the allsky downwelling shortwave radiation flux. For a very optically thick cloud the direct beam is extinguished but the diffuse component is equal to the total radiation, assuring that the total radiation transmission does not vanish. Therefore, total radiation extinction does not occur as quickly as might be expected. We also observe a slight increase in rCRE with increasing $N_{\mathrm{d}}$. The rCRE is more sensitive to changes in $N_{\mathrm{d}}$ at moderate LWP values (between 50 and $100 \mathrm{~g} \mathrm{~m}^{-2}$ ). Also, for a fixed LWP, the difference between the rCRE obtained for $N_{\mathrm{d}}=200 \mathrm{~cm}^{-3}$ and $N_{\mathrm{d}}=500 \mathrm{~cm}^{-3}$ is larger than the rCRE difference obtained using the larger $N_{\mathrm{d}}\left(N_{\mathrm{d}}=500 \mathrm{~cm}^{-3}\right.$ and $\left.N_{\mathrm{d}}=1000 \mathrm{~cm}^{-3}\right)$. The maximum radiative susceptibility occurs at $\mathrm{rCRE}=0.5$, and is higher for smaller $N_{\mathrm{d}}$ (Fig. 2b). This is consistent with previous results that predict that cleaner clouds are more susceptible to $A_{\mathrm{c}}$ changes than polluted clouds (Platnick and Twomey, 1994). The same authors also report that $A_{\mathrm{c}}$ sensitivity to $N_{\mathrm{d}}$ is a maximum when $A_{\mathrm{c}}$ is 0.5 , which is consistent with the larger separation between the curves in the moderate LWP range and for $\mathrm{rCRE}=0.5$.

\subsection{Broad statistical analysis of the observations}

To understand how the cloud radiative effect responds to changes in different parameters, a broad statistical analysis of the long-term data set obtained at SGP was undertaken. As LWP largely dominates rCRE (Eqs. 8 and 9, Fig. 2), the data were binned by rCRE and LWP. The bin sizes were 0.02 for rCRE and $5 \mathrm{~g} \mathrm{~m}^{-2}$ for LWP. For each bin the average of several different variables $\left(A_{\mathrm{i}}, D_{\mathrm{i}}, f_{\mathrm{c}}, \mathrm{LTS}, \tau_{\mathrm{c}}\right.$ and $\left.w^{\prime 2}\right)$ was calculated. This procedure allows us to isolate the LWP contribution to rCRE and to observe the associations of other properties with rCRE in the third (colored) dimension. To reduce variability due to poor sampling statistics, we require at least 15 points in each two-dimensional (2-D) bin. To observe the general trend of rCRE with LWP and the other variables, for this analysis, the broader LWP range was used. Solar zenith angle $\left(\theta_{0}\right)$ was limited to 80 degrees to avoid errors in cloud properties retrieved from the shortwave broadband radiative fluxes. The joint frequency distribution of rCRE and LWP for this data set is shown in the Supplement (Fig. S2).

Figure 3 shows that rCRE presents a clear increasing tendency with LWP, in agreement with the theoretical twostream approximation shown in Fig. 2. The distribution of LWP (Fig. 1a) indicates that the number of observations decreases with increasing LWP. The larger number of observations at lower LWP results in a larger vertical rCRE spread 

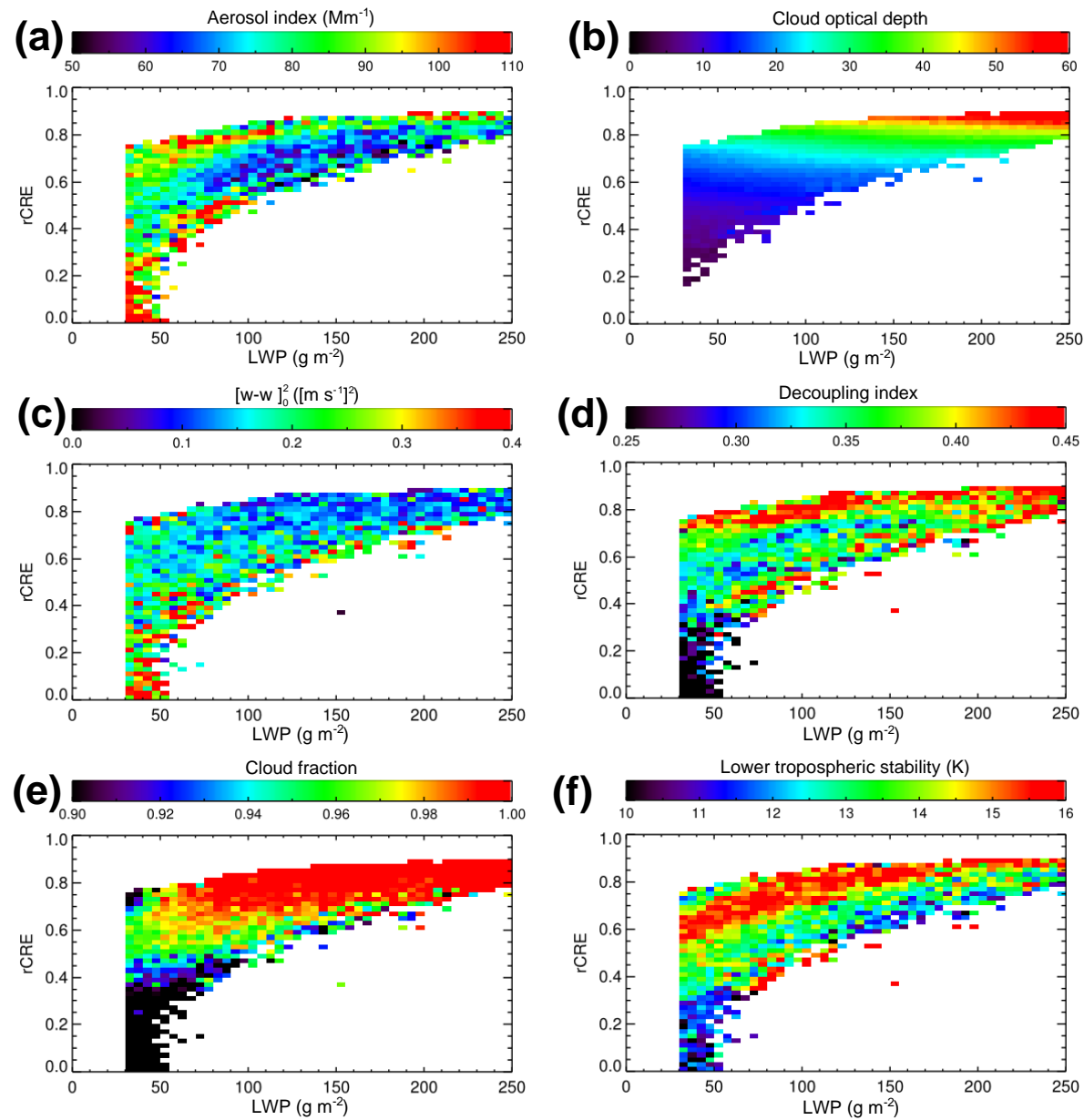

Figure 3. Relative cloud radiative effect as a function of liquid water path colored by (a) aerosol index, (b) cloud optical depth, (c) $w^{\prime 2}$, (d) decoupling index, (e) cloud fraction and (f) lower tropospheric stability.

for the low LWP values, compared to the high LWP. Several factors contribute to the variation of rCRE observed for a fixed LWP. According to Eq. (8), rCRE increases with $\theta_{0}$. Therefore, for a fixed LWP, differences in rCRE can be associated with different times of the day, and day of the year. Some rCRE differences could be related to the relatively small number of broken-cloud events that (i) reduce rCRE due to the smaller $f_{\mathrm{c}}$ associated with this cloud type; and (ii) introduce the possibility of 3-D radiative effects (e.g., Wen et al., 2007) or other retrieval errors, and therefore deviations from the simple two-stream model approximations that form the basis of the rCRE analysis. This further contributes to the vertical spread of points at low LWP.

For the liquid clouds that meet our analysis criteria, two different cloud types are identified: (i) broken-cumulus clouds characterized by lower mean $f_{\mathrm{c}}$ and higher $w^{\prime 2}$, and (ii) stratiform clouds associated with higher $f_{\mathrm{c}}$ and lower $w^{\prime 2}$. As most broken cumuli are concentrated in the lowest LWP range (usually $\mathrm{LWP}<100 \mathrm{~g} \mathrm{~m}^{-2}$ ) and have lower $f_{\mathrm{c}}$, they generally present smaller rCREs than stratiform clouds
(Eq. 4). There are exceptions where lower $f_{\mathrm{c}}$ in the lowest LWP range present higher rCRE. This may be due to the deviation from the two-stream model because of 3-D radiative effects, or some aerosol-related effect on the cloud properties. Since broken cumuli are associated with local convection, it is expected that this type of cloud exhibits a higher local coupling with the surface, and therefore a smaller $D_{\mathrm{i}}$, as observed in Fig. 3d. On the other hand, the stratiform clouds at SGP tend to be associated with deeper boundary layers, therefore leading to higher decoupling between the surface and the atmosphere. Stratiform clouds are also controlled by large-scale subsidence and exhibit a higher LTS than broken cumuli (Fig. 3f). The joint probability distribution function of $D_{\mathrm{i}}$ and $f_{\mathrm{c}}$ shows that low $f_{\mathrm{c}}$ cases are generally only observed when $D_{\mathrm{i}}$ is low (Fig. 4), with the exception of a few spurious data points.

Figure $3 b$ shows the strong dependence of $\tau_{c}$ on LWP, in agreement with Eq. (9). The dependence of rCRE on $\tau_{\mathrm{c}}$ is also easily identified. As $\tau_{\mathrm{c}}$ is only retrieved for $f_{\mathrm{c}}>0.9$, low rCRE values do not appear in Fig. 3b. For a fixed LWP, 


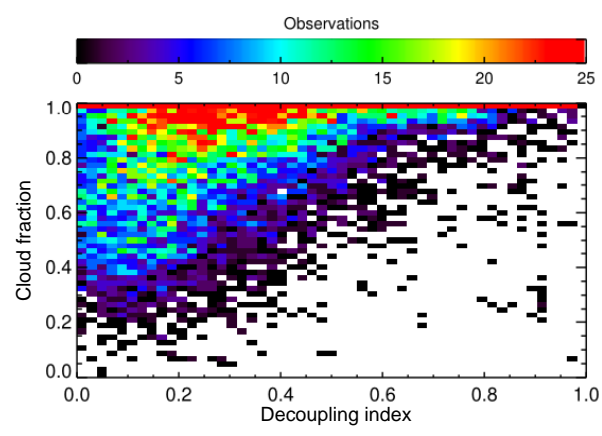

Figure 4. Joint probability distribution function of $D_{\mathrm{i}}$ and $f_{\mathrm{c}}$ obtained from 14 years of observations at SGP.

rCRE exhibits a weak trend with $A_{\text {i }}$ (Fig. 3a). When LWP is smaller than about $100 \mathrm{~g} \mathrm{~m}^{-2}$, this trend seems to occur in both directions, indicating that both high and low rCRE can be observed in more polluted conditions. One could infer that the positive trend is due to cloud microphysical changes caused by higher aerosol loading, while the negative trend could be due to the semi-direct effect of aerosol on clouds. We found no evidence of significant aerosol absorption for these cases. Meteorology also impacts the system and influences the rCRE. For example, different cloud dynamics could be linked to both changes in rCRE and in aerosol concentration. To understand the role that meteorology plays on the rCRE, some dynamical indices are now considered.

Higher turbulence facilitates more efficient droplet activation. Therefore, considering that for a constant LWP variation in $A_{\mathrm{c}}$ is due to changes in $N_{\mathrm{d}}$, it is expected that more turbulence would result in more droplets and higher cloud radiative effect (Feingold et al., 2003). However, Fig. 3c shows that for a fixed LWP there is a weak dependence of rCRE on $w^{\prime 2}$, with higher rCRE usually occurring for weaker turbulence. This result confirms that in most cases the rCRE is more dependent on macroscale cloud properties, such as LWP and $f_{\mathrm{c}}$, than on cloud microphysics. For example, in most cases higher turbulence is associated with broken cumuli that present lower $f_{\mathrm{c}}$, and therefore lower rCRE.

The correlation coefficients between the mean $f_{\mathrm{c}}$, LTS and $D_{\mathrm{i}}$ (Fig. 3d-f) were calculated. The correlation between $f_{\mathrm{c}}$ and $D_{\mathrm{i}}\left(\rho_{f_{\mathrm{c}}, D_{\mathrm{i}}}=0.72\right)$ is larger than the correlation between $f_{\mathrm{c}}$ and LTS $\left(\rho_{f_{\mathrm{c}} \text {,LTS }}=0.55\right)$. The correlation between LTS and $D_{\mathrm{i}}$ is also positive, with $\rho_{\mathrm{LTS}, \mathrm{Di}}=0.54$. As previously mentioned, LTS and $f_{\mathrm{c}}$ are expected to correlate well for low stratiform clouds. However, as the data in Fig. 3 also include some broken clouds, $\rho_{f_{\mathrm{c}} \text {,LTS }}$ is not as high as in previous assessments that only analyzed stratiform clouds (e.g., Klein and Hartmann, 1993; Wood and Bretherton, 2006). We hypothesize that the stronger $\rho_{f_{\mathrm{c}}, D_{\mathrm{i}}}$ compared to $\rho_{f_{\mathrm{c}} \text {, LTS }}$ is a consequence of two factors: (i) $D_{\mathrm{i}}$ is calculated for each cloud element and is therefore closely connected to the local cloud conditions, and (ii) LTS is based on the potential tem- perature at $700 \mathrm{hPa}$, which may not always be relevant to the local cloud conditions.

Both meteorological indices used in the analysis, LTS and $D_{\mathrm{i}}$, as well as $f_{\mathrm{c}}$ (Fig. $3 \mathrm{~d}-\mathrm{f}$ ), impart a less ambiguous signal in rCRE than does $A_{\mathrm{i}}$ (Fig. 3a). Figure $3 \mathrm{~d}-\mathrm{f}$ show that, on average, the rCRE is larger for less coupled atmospheric conditions, higher LTS and higher $f_{\mathrm{c}}$, associated with solid stratiform clouds. Figure $3 \mathrm{e}$ shows considerable $f_{\mathrm{c}}$ changes that dominate rCRE variability at low LWP. These results confirm that, in most cases, the cloud radiative effect is more closely related to cloud macroscopic variables than to cloud microphysics. At low LWP and higher rCRE, we find lower cloud fractions, which could indeed indicate the predominance of a microphysical effect. Some higher turbulence values are found here along with moderate aerosol index, but unfortunately those data are somewhat ambiguous and may suffer from 3-D radiative effects or other retrieval error.

The analysis performed in Fig. 3 provides useful information regarding how rCRE relates to macroscopic cloud properties, aerosol and meteorological indices. However, as observed in Eq. (8), rCRE also depends on $\theta_{0}$. In fact, rCRE varies slowly with $\theta_{0}$ for lower $\theta_{0}$ values, but shows a strong dependence on $\theta_{0}$ for higher angles. This intrinsic dependence of rCRE on $\theta_{0}$ does not allow us to isolate the effects on rCRE due solely to other properties from the effects caused by solar illumination angle. To reduce this influence, only cases where $\cos \left(\theta_{0}\right) \geq 0.6$ were considered for further analysis. This limit was selected such as to maximize the amount of data analyzed and at the same time, minimize the effects of $\theta_{0}$ on rCRE. Figure 5 shows rCRE as a function of LWP and the same variables analyzed in Fig. 3, when $\cos \left(\theta_{0}\right) \geq 0.6$. We note a priori that this filter preferentially removes early morning and late afternoon data, with more data loss in the wintertime. Whereas $18 \%$ of the observations in Fig. 3 were obtained during wintertime, due to the larger $\theta_{0}$ restriction, for Fig. 5 this number is reduced to only $2 \%$.

Figure 5 shows that the general trends of rCRE with these variables do not change significantly for aerosol and $\tau_{\mathrm{c}}$, when $\theta_{0}$ is limited. However, for $D_{\mathrm{i}}, f_{\mathrm{c}}, w^{\prime 2}$, and LTS the rCRE trends at fixed LWP are reduced compared to Fig. 3. One of the explanations for this behavior is that, as these variables have a marked diurnal cycle, limiting $\theta_{0}$ significantly reduces their variability. For example, higher $D_{\mathrm{i}}$ values are usually observed during early morning and late afternoon. Therefore, when only low $\theta_{0}$ values are considered, these higher $D_{\mathrm{i}}$ observations will not appear as frequently in the data set. On the other hand, as higher LWP values are associated with higher $f_{\mathrm{c}}$, higher $D_{\mathrm{i}}$ and lower $w^{\prime 2}$ values, high $\mathrm{rCRE}$ values will likely be observed when these macroscopic properties and thermodynamic conditions are met. The diurnal cycle of $D_{\mathrm{i}}$ will be further discussed in Sect. 3.5. Besides these factors, as the data set is dominated by $f_{\mathrm{c}} \sim 1$, for a fixed LWP and low $\theta_{0}$, differences in rCRE should be dominated by micro- 

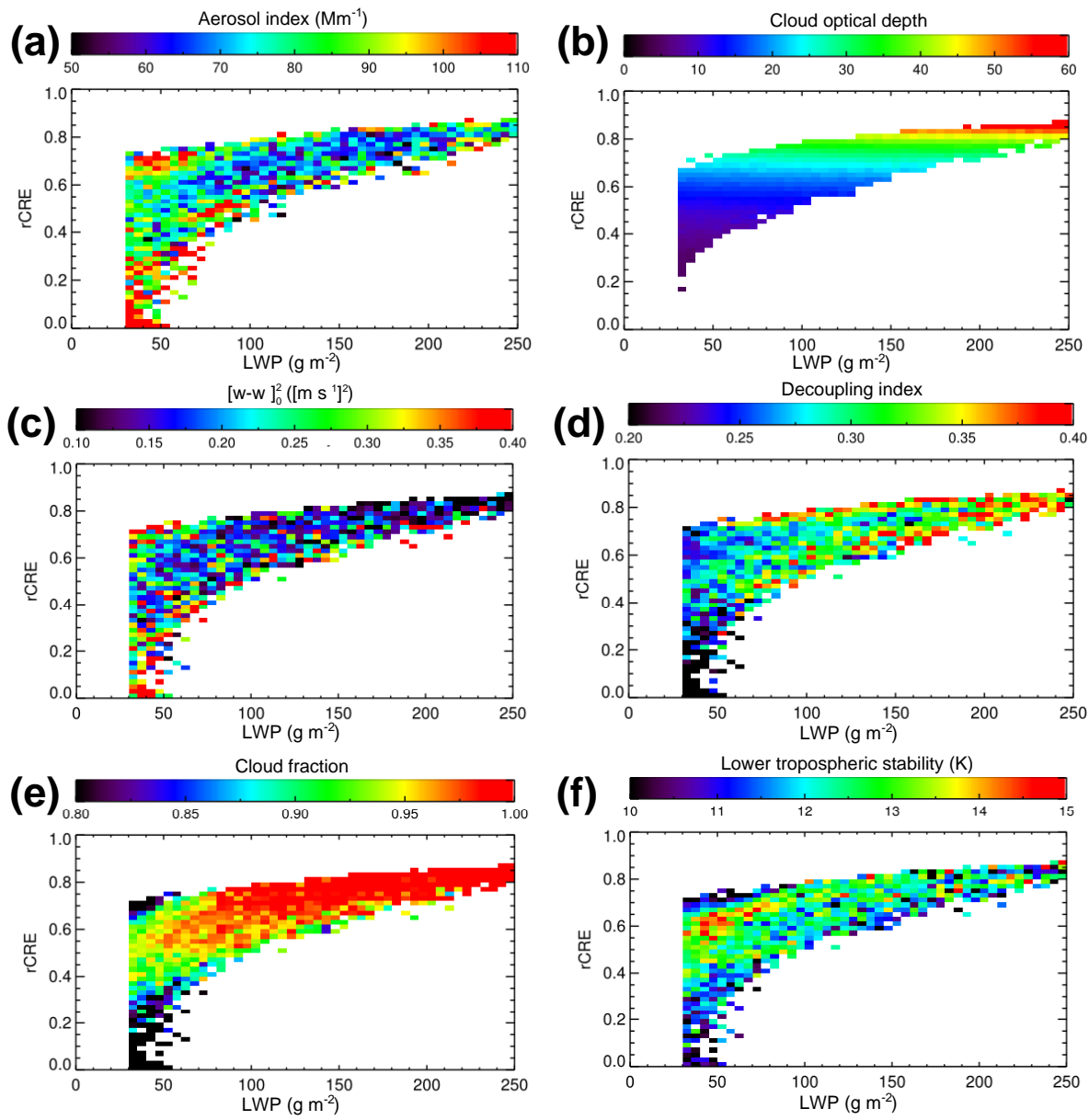

Figure 5. Relative cloud radiative effect as a function of liquid water path colored by (a) aerosol index, (b) cloud optical depth, (c) $w^{\prime 2}$, (d) decoupling index, (e) cloud fraction and (f) lower tropospheric stability for $\cos \left(\theta_{0}\right) \geq 0.6$.

physical influences. However, with the convolution of $f_{\mathrm{c}}$ and aerosol it is hard to definitively untangle these effects.

Cloud albedo was also analyzed as a function of LWP and the six other variables analyzed in Figs. 3 and 5. However, as $\mathrm{rCRE}$ is directly proportional to the product of $A_{\mathrm{c}}$ and $f_{\mathrm{c}}$ (Eq. 4) and most of the observations are concentrated at the same cloud fraction bin (Fig. 1b), the results obtained for $A_{\mathrm{c}}$ are very similar to the ones obtained for rCRE and are therefore not shown here. To isolate the effects of $f_{\mathrm{c}}$ and $A_{\mathrm{c}}$ on rCRE, the variation of $A_{\mathrm{c}}$ with five key variables (LWP, $A_{\mathrm{i}}$, $w^{\prime 2}, D_{\mathrm{i}}$ and LTS $)$ for completely overcast conditions $\left(f_{\mathrm{c}}=1\right)$ was analyzed (Fig. 6). For this analysis only cases observed when $\cos \left(\theta_{0}\right) \geq 0.6$ were considered. The joint distribution of these variables for this more restrictive data set is shown in the Supplement (Fig. S3). Figure 6 shows that, for this more restrictive range of $\theta_{0}$ and $f_{\mathrm{c}}=1, A_{\mathrm{c}}$ does not show strong, systematic variations with any of these variables. For low LWP, there is a small number of points with high $A_{\mathrm{i}}$ and high $A_{\mathrm{c}}$, which could be related to microphysical processes. It also seems that lower LWP values, associated with higher $A_{\mathrm{c}}$ are largely observed when stability is higher (high LTS), except where aerosol concentrations are highest. To fully address the impact of these variables on $A_{\mathrm{c}}$ would require further detailed analysis of the high-resolution data, rather than a broad statistical analysis, which is deferred to future work.

Since high $f_{\mathrm{c}}$ scenes dominate the data (Fig. 1b) and LWP plays a central role in cloud radiative responses, we attempted to identify and compare the signals due to LWP with those due to aerosol on rCRE. Daily correlations between rCRE and these two key variables ( $A_{\mathrm{i}}$ and LWP) were analyzed. For this analysis, the LWP range was restricted to avoid drizzle and uncertain retrievals, as explained in Sect. 3.2. Cases that had less than 25 points per day were excluded from this analysis. In the original database, 1093 days fit the low, warm, non-precipitating clouds criteria. After selecting cases that satisfied the minimum requisite number of points per day, low $\theta_{0}\left(\cos \left(\theta_{0}\right) \geq 0.6\right)$, and had non-missing coincident retrievals of rCRE, LWP and $A_{\mathrm{i}}$, only 111 days remained. The histograms of the distribution of the correlations between rCRE and $A_{\mathrm{i}}\left(\rho_{\mathrm{rCRE}}, A_{\mathrm{i}}\right)$ and rCRE and LWP $\left(\rho_{\text {rCRE,LWP }}\right)$ are shown in Fig. 7. 

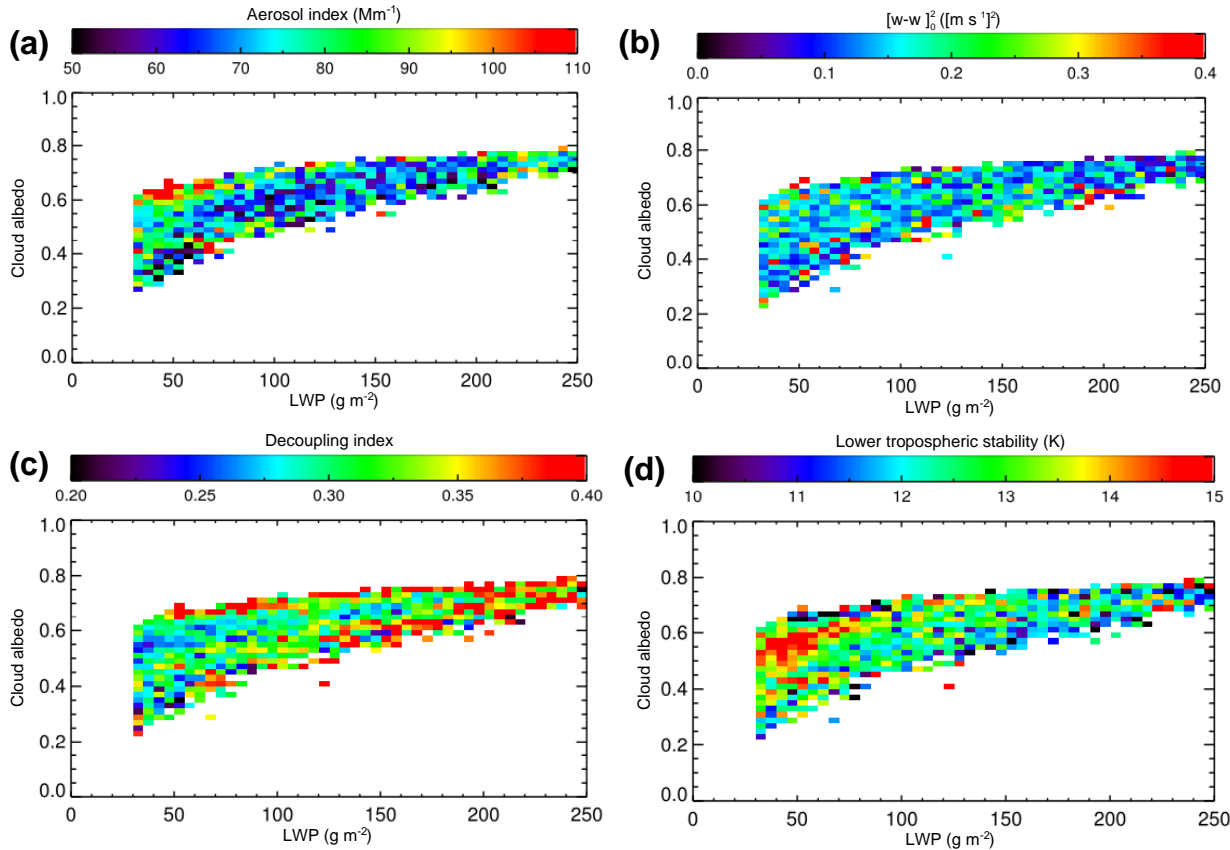

Figure 6. Cloud albedo as a function of liquid water path colored by (a) aerosol index, (b) $w^{\prime 2}$, (c) decoupling index and (d) lower tropospheric stability, for completely overcast conditions $\left(f_{\mathrm{c}}=1\right)$ for $\cos \left(\theta_{0}\right) \geq 0.6$.

Figure 7a corroborates Fig. 3a, showing that rCRE and $A_{\mathrm{i}}$ can either be positively or negatively correlated. The proportion of negatively and positively correlated cases is roughly $50 / 50$ for $\rho_{\mathrm{rCRE}, A_{\mathrm{i}}}$. On the other hand, rCRE and LWP show a much higher positive correlation than $\mathrm{rCRE}$ and $A_{\mathrm{i}}$ (Fig. 7b). The histograms show that $\rho_{\mathrm{rCRE}, A_{\mathrm{i}}}$ is on average $-0.01 \pm 0.03$ while $\rho_{\mathrm{rCRE}, \mathrm{LWP}}$ was on average $0.56 \pm 0.02$. For about $98 \%$ of the cases rCRE and LWP are positively correlated. Therefore, we can infer that LWP clearly dominates the cloud radiative effect, while the aerosol signal on rCRE is ambiguous.

\subsection{Case studies}

The results shown in the previous sections provide broad insight into the general macroscopic behavior observed for warm clouds at SGP and the potential role of aerosol in driving this behavior. For a deeper understanding of the processes related to those long-term trends, some cases were further analyzed. 2 days that presented relatively high positive or negative correlations between $\mathrm{rCRE}$ and $A_{\mathrm{i}}$ were selected and investigated further. The selected case studies have a long time series, with at least $6 \mathrm{~h}$ of rCRE retrievals, in addition to continuous measurements of relevant properties, providing a good sample of observations.

\subsubsection{Case study 1: positive correlation between rCRE and $A_{\mathrm{i}}$}

Figure 8 shows the time series of several relevant measurements, such as $\tau_{\mathrm{c}}$, LWP, rCRE, $A_{\mathrm{i}}$ and $D_{\mathrm{i}}$, for 9 January 2006. The time series of the vertical profile of radar $Z$ is also shown. Since the rCRE can only be measured during sunlit periods $\left(\theta_{0}<80^{\circ}\right)$, this analysis focuses on that period. Due to the detection of multiple layers of clouds after 20:00 UTC, the plots are restricted to the period from 12:00 to 20:00 UTC (06:00 to 14:00 LT). The correlation between rCRE and $A_{\mathrm{i}}$ for this day is positive and about 0.75 .

The radar reflectivity indicates that this case represents a solid stratiform cloud that begins to develop with the boundary layer at $\sim 12: 00 \mathrm{UTC}$ (Fig. 8 b). $h_{\mathrm{CT}}$ peaks around $1 \mathrm{~km}$ and remains constant after 16:00 UTC. Note that according to the radar reflectivity it is highly unlikely that this day was affected by precipitation.

The strong positive correlation between $\mathrm{rCRE}, \tau_{\mathrm{c}}$ and LWP is also noted (Fig. 8a). As previously pointed out these three variables are closely related (Eqs. 8 and 9). On that day, radiometric measurements were only available after $\sim$ 14:00 UTC, so rCRE and $\tau_{\mathrm{c}}$ were only retrieved after that time.

The increase in the incoming solar radiation absorbed by the atmosphere and reaching the surface, warms the atmosphere. The LCL increases with time until it stabilizes at $600 \mathrm{~m}$ around 18:00 UTC. The diurnal cycle of shortwave radiation affects the coupling between the surface and the 

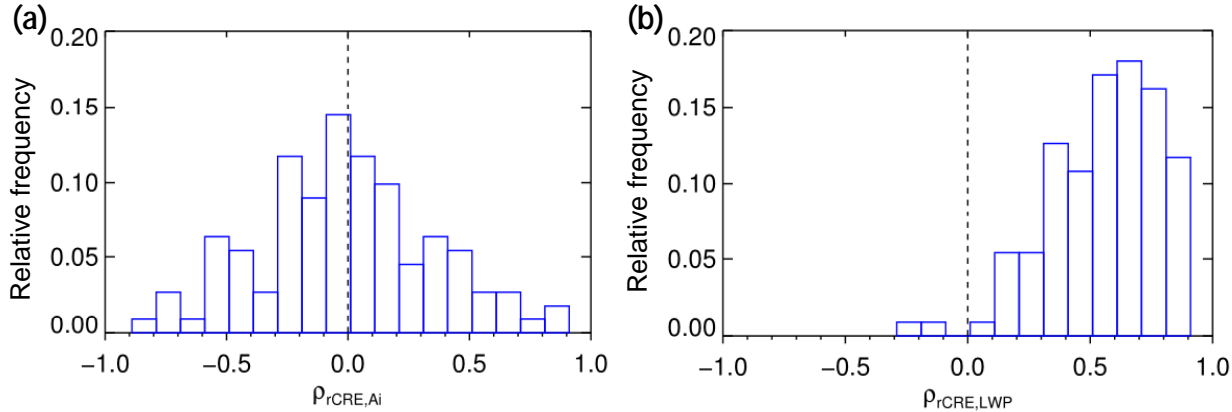

Figure 7. Daily distribution of the (a) correlation between the relative cloud radiative effect (rCRE) and aerosol index $\left(A_{\mathrm{i}}\right)$ and $(\mathbf{b})$ the correlation between rCRE and liquid water path (LWP) for $\cos \left(\theta_{0}\right) \geq 0.6$.

boundary layer leading to more coupled conditions in the afternoon (Fig. 8d). The relation between $D_{\mathrm{i}}$ and solar radiation is further explored in Sect. 3.4.2 and 3.5.

After about 16:00 UTC both $A_{\mathrm{i}}$ and LWP, decrease (Fig. 8a). The mechanisms that lead to the decreases are most likely associated with entrainment and drying as the boundary layer deepens. (The relative humidity RH time series shows that surface $\mathrm{RH}$ decreases with time, until about 18:00 UTC, when it stabilizes at about 0.7.) Dilution due to the increase in the boundary layer depth likely explains the drop in surface aerosol concentration and decrease in $A_{\mathrm{i}}$.

Next, we aim to understand how the co-variability between LWP and $A_{\mathrm{i}}$ could be linked to the response of rCRE to these two variables. Figure $9 \mathrm{a}-\mathrm{c}$ show the correlations between rCRE and $A_{\mathrm{i}}\left(\rho_{\mathrm{rCRE}}, A_{\mathrm{i}}\right), \mathrm{rCRE}$ and LWP $\left(\rho_{\mathrm{rCRE}, \mathrm{LWP}}\right)$ and LWP and $A_{\mathrm{i}}\left(\rho_{\mathrm{LWP}, A_{\mathrm{i}}}\right)$ for the selected day. Only points that have coincident measurements of all three variables rCRE, LWP and $A_{\mathrm{i}}$ - are used. The number of valid points is 329.

For this day, all correlations are positive, with $\rho_{\mathrm{rCRE}, A_{\mathrm{i}}}=0.75, \quad \rho_{\mathrm{rCRE}, \mathrm{LWP}}=0.82 \quad$ and $\quad \rho_{\mathrm{LWP}, A_{\mathrm{i}}}=0.50$. The results and theory shown in Sect. 3.2 and 3.3, indicate that the changes in LWP drive changes in rCRE. However, microphysical responses also need to be considered. For a vertically homogeneous cloud, droplet effective radius $\left(r_{\mathrm{e}}\right)$ can be calculated as a function of LWP and the $\tau_{\mathrm{c}}$ (Stephens, 1978).

$r_{\mathrm{e}}=1.5 \frac{\mathrm{LWP}}{\rho_{\mathrm{W}} \tau_{\mathrm{c}}}$,

where LWP is given in $\mathrm{g} \mathrm{m}^{-2}, r_{\mathrm{e}}$ is given in $\mu \mathrm{m}$ and $\rho_{\mathrm{W}}$ is the density of liquid water in $\mathrm{g} \mathrm{cm}^{-3}$.

For a cloud with constant LWP, a measure of the strength of aerosol-cloud interaction $(\alpha)$ can be obtained from the relative change between $r_{\mathrm{e}}$ and $A_{\mathrm{i}}$ :

$\alpha=-\left.\frac{\partial \ln r_{\mathrm{e}}}{\partial \ln A_{\mathrm{i}}}\right|_{\mathrm{LWP}}$
According to this definition, $\alpha$ is expected to be positive and vary between 0 and 0.33 , with a typical value of 0.23 (Feingold et al., 2001; McComiskey and Feingold, 2012).

To assess the microphysical effect of aerosols on clouds, $r_{\mathrm{e}}$ was calculated using Eq. (11) and plotted as a function of $A_{\mathrm{i}}$. In an attempt to isolate the aerosol effects on $r_{\mathrm{e}}$, the data set was divided into three LWP bins. For each bin, the linear regression between the logarithm of $r_{\mathrm{e}}$ and logarithm of $A_{\mathrm{i}}$ was obtained. The slope of each linear fit provides the parameter $\alpha$ (Fig. 9d).

For this case, $r_{\mathrm{e}}$ varied between 2 and $7 \mu \mathrm{m}$ and $\alpha$ is positive, as expected. The values obtained for $\alpha$ are within the expected range, except for the higher LWP category (Fig. 9d). However, there is a large variability in the magnitude of $\alpha$. For the highest LWP range, $\alpha$ is about twice the value obtained for the mid-range LWP.

The question remains whether the positive correlation between rCRE and $A_{\mathrm{i}}$ is a result of the positive correlation between rCRE and LWP observed on that and many days in this data set (Fig. 3) - i.e., a macrophysical response - or whether it is due to the negative correlation between $r_{\mathrm{e}}$ and $A_{\mathrm{i}}-$ i.e., a microphysical response. This single case study suggests that both contributions are possible, but raises concerns about being too reliant on the microphysical response as an indicator of aerosol-related rCRE.

\subsubsection{Case study 2: negative correlation between rCRE and $A_{\mathrm{i}}$}

A case that shows a high negative correlation between rCRE and $A_{\mathrm{i}}, 26$ April 2006, was also selected and analyzed in detail. Similar to the previous case, Fig. 10 shows the time series of some of the relevant measurements and retrievals for this day. As the cloud completely vanished during late afternoon the analysis time frame was once again restricted to between 12:00 and 20:00 UTC. The radar profile is shown from earlier in the day (05:00 UTC and on), as some drizzle was detected during nighttime. The drizzle may have scavenged the aerosol particles and could explain the low $A_{\mathrm{i}}$ val- 
(a)
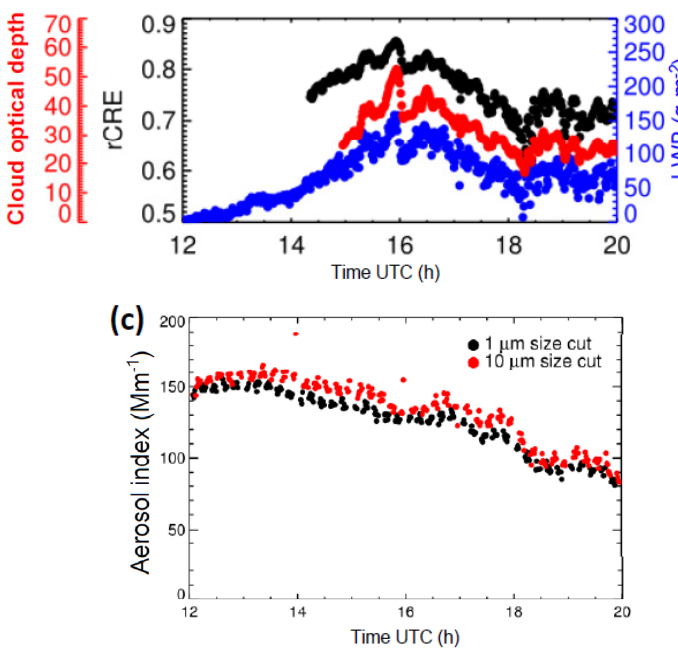

(b)

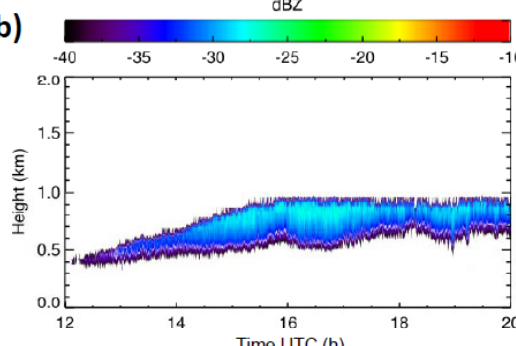

(d)

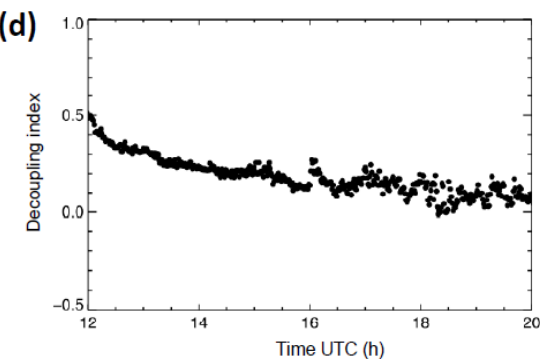

Figure 8. Time series of (a) rCRE, cloud optical depth and LWP, (b) vertical profile of radar reflectivity, (c) aerosol index and (d) decoupling index for 9 January 2006.
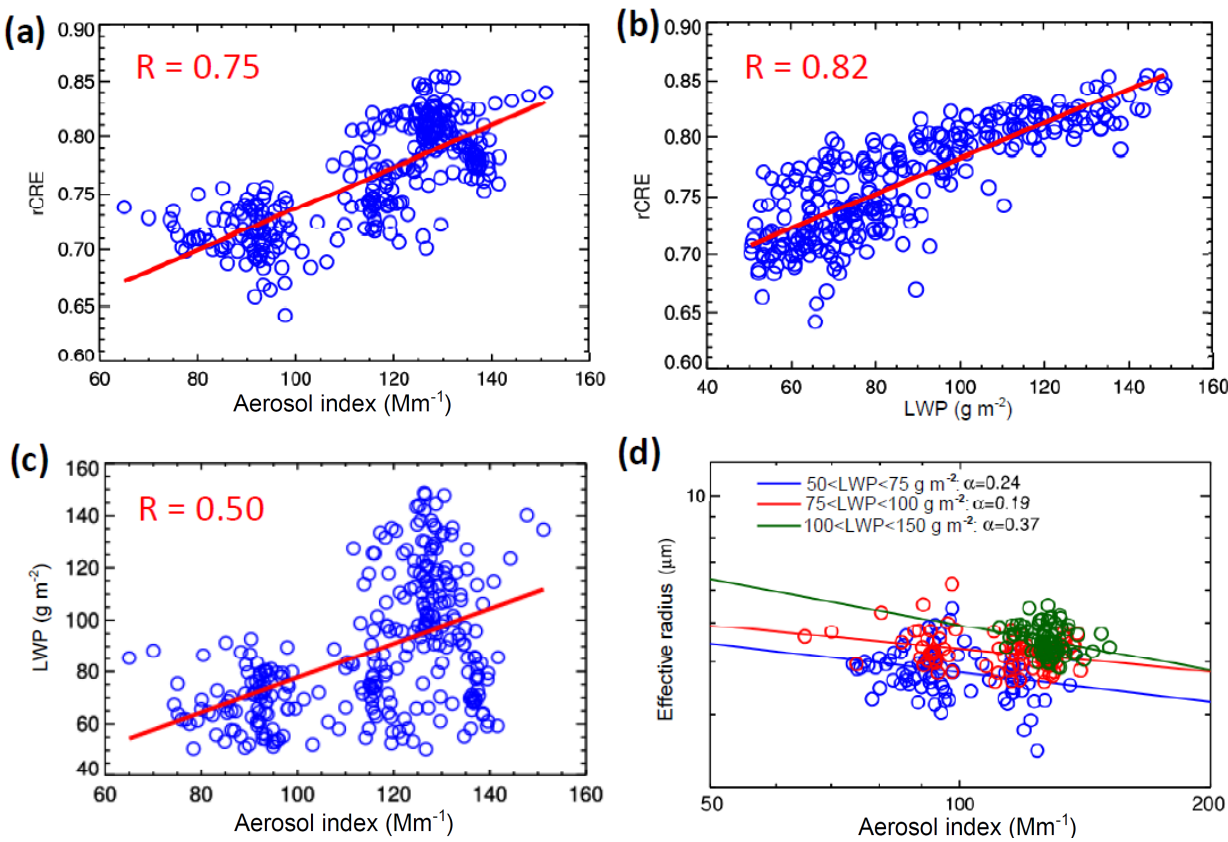

Figure 9. Correlation between (a) rCRE and $A_{\mathrm{i}}$, (b) rCRE and LWP, (c) LWP and $A_{\mathrm{i}}$ and (d) effective radius as a function of $A_{\mathrm{i}}$ grouped by LWP for 9 January 2006.

ues shown in Fig. 10c, through $\sim$ 14:50 UTC. The red line indicates daytime in Fig. 10b.

Once again, a strong positive correlation between rCRE, $\tau_{\mathrm{c}}$ and LWP is observed.

The evolution of $D_{\mathrm{i}}$ is similar to the previous case, indicating that for both days the coupling between atmosphere and surface is driven by the diurnal cycle of radiation, rather than by other variables. This day was much warmer than the previous case and presented higher LCL values and lower surface RH. The surface temperature differences between the two days varied from 6 to $10 \mathrm{~K}$ during the period analyzed.

The temporal evolution of LWP and the vertical profile of reflectivity for 26 April 2006 (Fig. 10b-c) indicate that at about 14:00 UTC the stratiform cloud begins to dissipate, transitioning to broken cumuli after $\sim$ 17:00 UTC. The decrease in both LWP and $f_{\mathrm{c}}$ after 14:00 UTC coincides with 
(a)
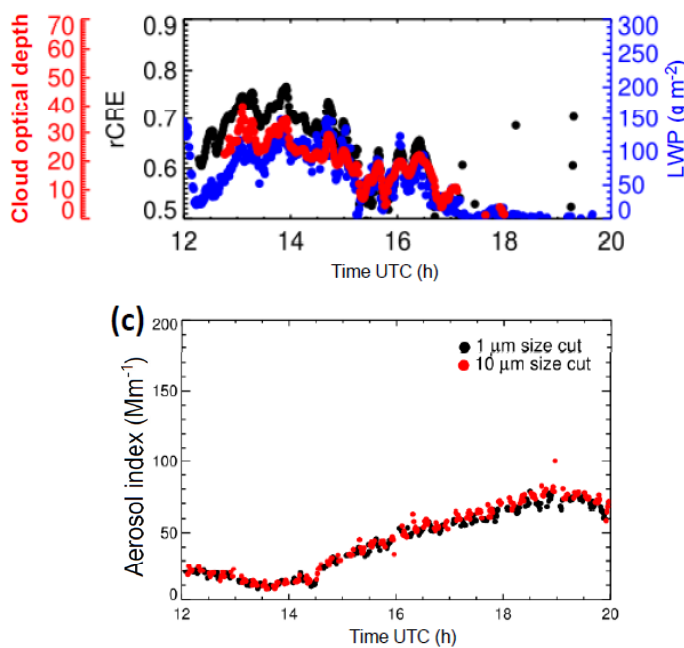

(b)

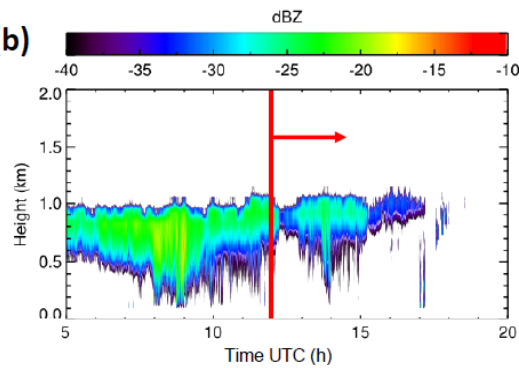

(d)

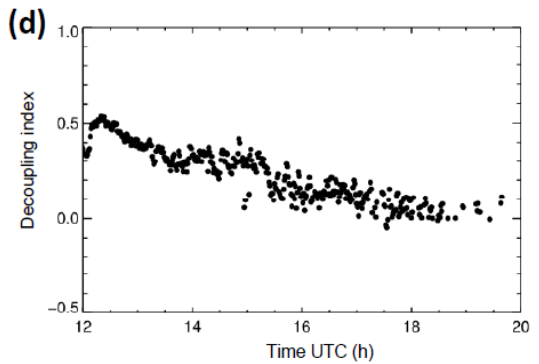

Figure 10. Time series of (a) rCRE, cloud optical depth and LWP, (b) radar reflectivity, (c) aerosol index and (d) decoupling index for 26 April 2006.
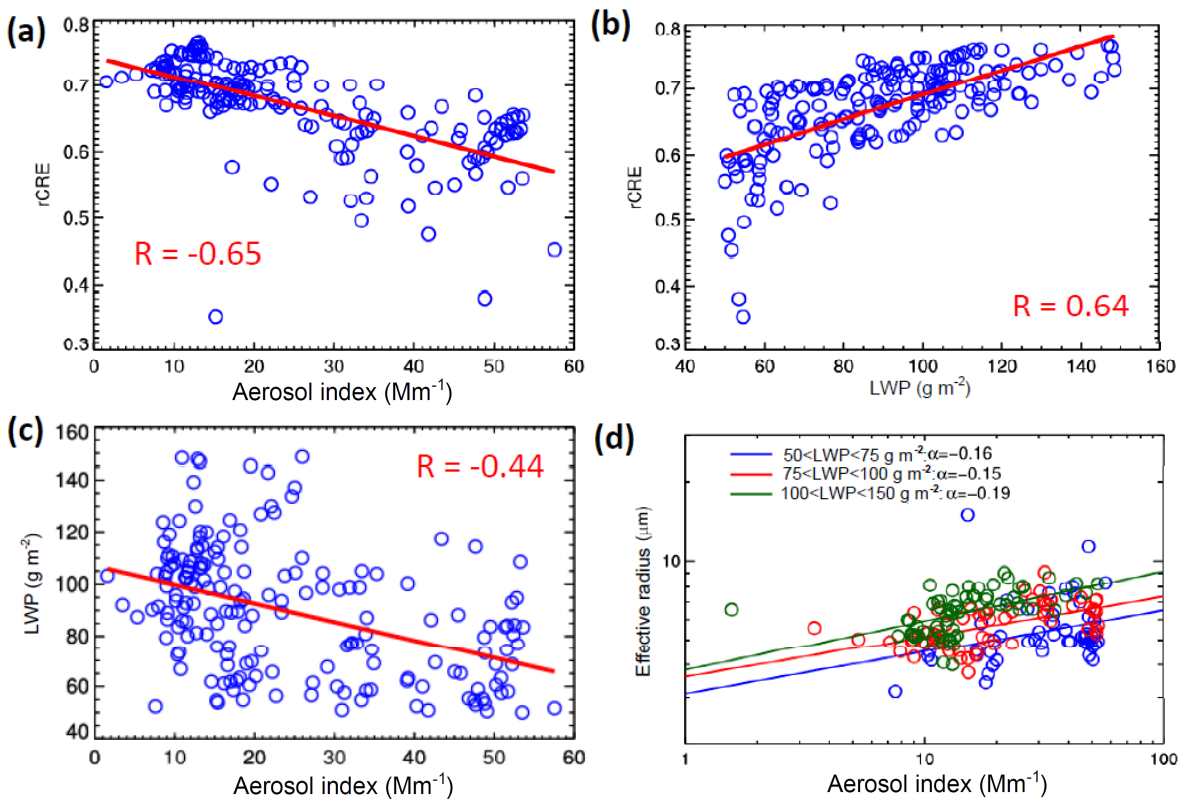

Figure 11. Correlation between (a) rCRE and $A_{\mathrm{i}}$, (b) rCRE and LWP, (c) LWP and $A_{\mathrm{i}}$ and (d) effective radius as a function of $A_{\mathrm{i}}$ grouped by LWP for 26 April 2006.

an increase in $A_{\mathrm{i}}$. One hypothesis to explain this behavior is that boundary layer deepening and entrainment drying reduce cloud amount as the day progresses. $D_{\mathrm{i}}$ decreases because when clouds do form (a prerequisite for calculating $D_{\mathrm{i}}$ ) the local coupling is relatively strong. The increase in $A_{\mathrm{i}}$ from a low post-drizzle clean atmosphere could be a result of a combination of surface sources, transport and entrainment of free tropospheric air. It is also possible that cloud breakup may be caused by the aerosol semi-direct effect; however, $A_{\mathrm{i}}$ was lower on this day and the analysis of the Ångström exponent and single scattering albedo (SSA) indicate that there are no significant differences in aerosol intensive properties (and thus, perhaps in aerosol type) between this and the previous case. The mean Ångström exponent at $1 \mu \mathrm{m}$ cut size for case 2 was $2.274 \pm 0.010$, while in the previous case it was $2.107 \pm 0.008$. The mean SSA was $0.9721 \pm 0.0012$ and $0.9826 \pm 0.0004$, for case 2 and case 1 , respectively. The difference in the uncertainty indicates that for case 2 , both the 
Ångström exponent and SSA fluctuate more. Finally, while one might want to invoke a role for the increasing aerosol evaporating smaller droplets more efficiently, which in turn would decrease $f_{\mathrm{c}}$ (Small et al., 2009), these aerosol loadings are relatively low and, as already discussed in Sect. 3.3, many other dynamical features influence $f_{\mathrm{c}}$ and cloud development, especially during the daytime.

The correlations between rCRE, LWP and $A_{\mathrm{i}}$ for case 2 are shown in Fig. 11a-c. The microphysical effect of aerosol on drop size is shown in Fig. 11d. The number of valid points for this study case is 204 .

The correlation between $\mathrm{rCRE}$ and $A_{\mathrm{i}}$ is negative and equal to -0.65 for this case. The correlation between rCRE and LWP is 0.64 , smaller than in the previous case study, but still positive, as expected. Figure 11c shows that for case 2, LWP and $A_{\mathrm{i}}$ are negatively correlated with $\rho_{\mathrm{LWP}, A_{\mathrm{i}}}=-0.44$.

The $r_{\mathrm{e}}$ retrievals indicate that the sizes of most of the droplets analyzed in this case fall in the same range as the previous case study (between 3 and $10 \mu \mathrm{m}$ ). Here, however, $\alpha$ is negative (Fig. 11d), for which there is no physical explanation given the stratification by LWP and our expectation that drop size decreases with an increasing number of $\mathrm{CCN}$ for the same amount of condensed water (Twomey, 1977). This unexpected behavior could derive from a combination of factors: uncertainty in measurements, uncertainty in linear fits and possibly the rather broad LWP binning, among others. Given the unphysical $r_{\mathrm{e}}$ response to increasing aerosol, the positive correlation between rCRE and LWP, and the overwhelming contribution of macroscopic and dynamical variables to the cloud system compared to the aerosol signal discussed in Sect. 3.3, the results indicate that the observed negative correlation between rCRE and $A_{\mathrm{i}}$ is most likely due to the fact that LWP and aerosol are negatively correlated, presumably due to independent factors.

Most techniques employed to retrieve $\tau_{\mathrm{c}}$ using groundbased instruments rely on overcast conditions (e.g., Barnard et al., 2008; Min and Harrison, 1996). The technique of Xie and Liu (2013) can be used to retrieve $\tau_{\mathrm{c}}$ for lower cloud coverage. In Figs. 9d and $11 \mathrm{~d}, r_{\mathrm{e}}$ was calculated using retrievals of $\tau_{\mathrm{c}}$ from a broadband radiometer (RFA) following Barnard and Long (2004). Additionally, two other methods were used to retrieve $\tau_{\mathrm{c}}$ and $r_{\mathrm{e}}$ for the case studies highlighted above: the Multifilter Rotating Shadowband Radiometer (MFRSR; Turner and Min, 2004) and broadband radiometer retrievals by Xie and Liu (2013). Effective radii $r_{\mathrm{e}}$, determined from the measured LWP and each of the $\tau_{\mathrm{c}}$ retrievals, were used to obtain the aerosol-cloud interaction $(\alpha)$ slope (Table 2). Retrievals acquired when $\theta_{0}>70^{\circ}$ were excluded from this analysis as the measurements are less reliable at higher solar zenith angles and the retrievals diverged greatly at high $\theta_{0}$ in some cases. The different methodologies used to retrieve $\tau_{\mathrm{c}}$ result in different $\alpha$, and, for some cases, even the sign of the slopes disagree. The difference observed for $\alpha_{\text {RFA }}$ estimates shown in Table 2, compared to Figs. 9 and 11, is due to the

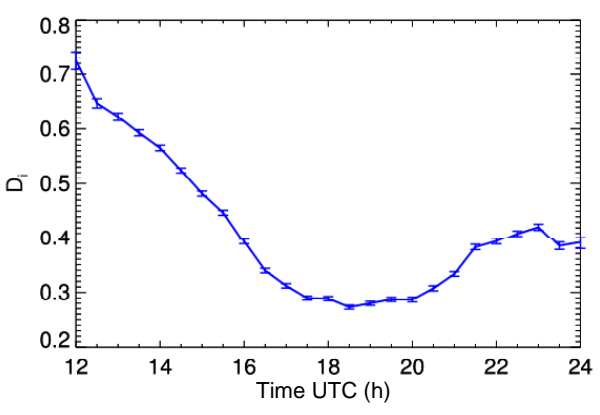

Figure 12. Mean diurnal cycle of the decoupling index $\left(D_{\mathrm{i}}\right)$ obtained using 14 years of retrievals at the SGP. Error bars indicate the standard deviation of the mean for each time bin.

restriction of collocation of data points among the three data sets and the $\theta_{0}<70^{\circ}$ threshold.

As emphasized above, this comparison raises concerns about reliance on $\alpha$ alone to quantify aerosol-related rCRE in terms of microphysical metrics. The requirement of binning by LWP leaves low statistics for calculating slopes in each bin and uncertainties in the slopes are high. Given the low statistics, differences in the retrievals can result in the large differences in $\alpha$ seen here, including changes in sign. These microphysical measures are useful for detecting aerosol effects on cloud properties, but are best used in conjunction with other measurements to fully understand the relevant physical processes. Using these measures for quantification of the aerosol indirect effect (the aerosol induced cloud radiative effect), especially in case studies where statistics are low, can be misleading. Studies that provide larger statistics may produce more meaningful quantifications (e.g., McComiskey et al., 2009), but will still contain biases inherent in any retrievals used to provide input properties to the calculation.

\subsection{Further generalizations}

The diurnal cycles of the $D_{\mathrm{i}}$, shown in two case studies of Sect. 3.4, were very similar, with higher $D_{\mathrm{i}}$ in the morning and lower $D_{\mathrm{i}}$ around 20:00 UTC (Figs. $8 \mathrm{~d}$ and 10d). To verify if this trend is generally observed, the complete time series obtained during this 14 year study was used. The data set was divided into $0.5 \mathrm{~h}$ bins and the mean diurnal cycle of $D_{\mathrm{i}}$ during daytime was analyzed (Fig. 12).

Figure 12 shows that the temporal evolution of $D_{\mathrm{i}}$ is strongly linked to the diurnal cycle of solar radiation. On average, the atmosphere is highly decoupled in the morning. As the sun rises, the surface gets warmer, and solar energy is transferred from the surface to the atmosphere, favoring more coupled conditions (lower $D_{\mathrm{i}}$ ). The higher coupling between the surface and the atmosphere increases turbulence. As the incoming solar radiation during the afternoon decreases, the atmosphere gradually cools. After 20:00 UTC, the boundary layer collapses leading to less coupled conditions in the late afternoon. 
Table 2. Slopes $\alpha$ and their uncertainty obtained using different $\tau_{\mathrm{c}}$ retrievals: from the Radiative Flux Analysis (RFA), using the Xie and Liu technique $(2013, \mathrm{XL})$ and using MFRSR measurements. Coincident retrievals of $\tau_{\mathrm{c}}$ from each retrieval acquired when $\theta_{0}<70^{\circ}$ for each day were used to calculate $\alpha$.

\begin{tabular}{lrrrr}
\hline & LWP $\left(\mathrm{g} \mathrm{m}^{-2}\right)$ & $\alpha_{\mathrm{RFA}}$ & $\alpha_{\mathrm{XL}}$ & $\alpha_{\text {MFRSR }}$ \\
\hline Case study 1 & $50-75$ & $0.27 \pm 0.09$ & $0.32 \pm 0.09$ & $0.23 \pm 0.07$ \\
& $75-100$ & $0.26 \pm 0.07$ & $-0.03 \pm 0.08$ & $0.25 \pm 0.06$ \\
& $100-150$ & $0.73 \pm 0.26$ & $0.58 \pm 0.30$ & $0.70 \pm 0.24$ \\
\hline Case study 2 & $50-75$ & $-0.01 \pm 0.09$ & $0.31 \pm 0.07$ & $0.10 \pm 0.06$ \\
& $75-100$ & $-0.09 \pm 0.04$ & $0.25 \pm 0.04$ & $0.07 \pm 0.03$ \\
& $100-150$ & $-0.23 \pm 0.04$ & $0.11 \pm 0.02$ & $-0.03 \pm 0.02$ \\
\hline
\end{tabular}

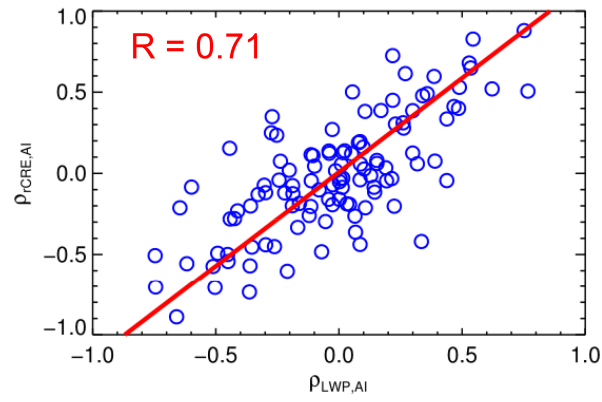

Figure 13. Correlation between $\mathrm{rCRE}$ and $A_{\mathrm{i}}\left(\rho_{\mathrm{rCRE}}, A_{\mathrm{i}}\right)$ vs. the correlation between $\mathrm{LWP}$ and $A_{\mathrm{i}}\left(\rho_{\mathrm{LWP}, A_{\mathrm{i}}}\right)$ for $\cos \left(\theta_{0}\right) \geq 0.6$.

The results shown in the previous section also indicate that, for these two case studies, the correlation between rCRE and $A_{\mathrm{i}}$ has the same sign as the correlation between LWP and $A_{\mathrm{i}}$ (Figs. 9 and 11). For the first case study, $\rho_{\mathrm{rCRE}}, A_{\mathrm{i}}$ and $\rho_{\mathrm{LWP}, A_{\mathrm{i}}}$ are positive, while for the second case study both correlations are negative. This suggests that the sign of $\rho_{\mathrm{rCRE}} A_{\mathrm{i}}$ is mainly determined by $\rho_{\mathrm{LWP}}, A_{\mathrm{i}}$. We now test the validity of this hypothesis and if this statement can be expanded for the whole data set. For each day the correlation between rCRE and $A_{\mathrm{i}}\left(\rho_{\mathrm{rCRE}} A_{\mathrm{i}}\right)$ and between LWP and $A_{\mathrm{i}}\left(\rho_{\mathrm{LWP}, A_{\mathrm{i}}}\right)$ were calculated. Figure 13 shows the results obtained for these correlations, where each point represents 1 day. This was done for the 111 days that had coincident measurements of the three variables $\left(A_{\mathrm{i}}, \mathrm{LWP}\right.$, and rCRE) at low $\theta_{0}$. An orthogonal linear fit of the observations was performed.

Figure 13 shows that this statement can be generalized. Usually, if $A_{\mathrm{i}}$ and LWP are positively (negatively) correlated, the correlation between rCRE and $A_{\mathrm{i}}$ is positive (negative). This relationship was further analyzed as a function of several variables $\left(A_{\mathrm{i}}, \mathrm{LWP}, D_{\mathrm{i}}, \tau_{\mathrm{c}}\right.$, wind direction, wind speed, surface $\mathrm{RH}, w^{\prime 2}$ ), none of which significantly influenced the results. Considering all the days analyzed, the correlation between $\rho_{\mathrm{rCRE}} A_{\mathrm{i}}$ and $\rho_{\mathrm{LWP}, A_{\mathrm{i}}}$ is 0.71 . Even when $\theta_{0}$ is not restricted, and therefore variations in $\theta_{0}$ might obscure this relationship, the correlation between $\rho_{\mathrm{rCRE}}, A_{\mathrm{i}}$ and $\rho_{\mathrm{LWP}, A_{\mathrm{i}}}$ is 0.54 . This result suggests that the aerosol signal observed in rCRE based on daily correlations may often be a misinterpretation of the positive relationship between rCRE and LWP. Once again, for the data set analyzed, which consists overwhelmingly of high $f_{\mathrm{c}}$ events, the cloud radiative effect appears to be predominantly driven by macroscopic variables rather than by microphysical responses.

Given the uncertainty in calculations of $\alpha$ (Table 2) the current work sounds a cautionary note regarding placing too much emphasis on microphysical metrics. This does not exclude the possibility of an aerosol influence on the cloud radiative effect but suggests that careful analysis should be done to quantify macrophysical relationships, such as those shown here. Moreover, consideration of the co-variability in aerosol and cloud macroscopic quantities (LWP in particular) has a strong influence on the detectability of aerosol-induced rCRE and therefore deserves attention (George and Wood, 2010; Feingold et al., 2016).

\section{Summary and conclusions}

A comprehensive study was performed to understand the relative effects of aerosols, macroscopic cloud properties and meteorological drivers on the radiative effect of low-level clouds. In all, 14 years of coincident ground-based clouds, aerosol and meteorological measurements over the SGP were analyzed. The impact of different physical properties on the instantaneous cloud radiative effect was studied. The data set was divided into rCRE and LWP bins and the mean values of properties such as $f_{\mathrm{c}}, \tau_{\mathrm{c}}, D_{\mathrm{i}}$, LTS, $A_{\mathrm{i}}$ and turbulence were analyzed. Most of the data are characterized by high $f_{\mathrm{c}}$ so that rCRE is predominantly a function of $A_{\mathrm{c}}$ (Eq. 4), which is in turn a strong function of LWP, and to a lesser extent drop concentration (Eqs. 7 and 9). Whereas a strong dependence of rCRE on LWP is clearly identified, the average over the whole data set shows an ambiguous influence of aerosol on rCRE. For low LWP, polluted conditions are associated with both high and low rCRE.

Since LWP is such a key driver of rCRE, the impact of the aerosol and of LWP on the cloud radiative effect were compared by assessing the daily correlations between rCRE and $A_{\mathrm{i}}$ and rCRE and LWP. While the daily distribution of 
$\rho_{\text {rCRE,LWP }}$ shows a clear positive signal, the daily distribution of $\rho_{\mathrm{rCRE}} A_{\mathrm{i}}$ is centered around 0 , confirming the previous statement that high aerosol concentrations can be associated with both higher and lower rCRE.

Case studies that showed both positive and negative correlations between $\mathrm{rCRE}$ and $A_{\mathrm{i}}$ were further investigated. For these 2 selected days, rCRE was positively (negatively) correlated with $A_{\mathrm{i}}$ when $A_{\mathrm{i}}$ and LWP were positively (negatively) correlated. This behavior can be generalized to the other days analyzed. The case studies also show that microphysical metrics to estimate aerosol-cloud interaction (Eq. 10) are very uncertain and reliance on these estimates to quantify aerosol-related rCRE can be misleading.

The diurnal cycle of $D_{\mathrm{i}}$ over the SGP is strongly driven by the diurnal cycle of solar radiation. Both, LTS and $D_{\mathrm{i}}$ are highly correlated with $f_{\mathrm{c}}$ however $\rho_{f_{\mathrm{c}}, D_{\mathrm{i}}}$ is larger than

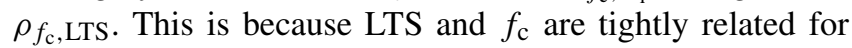
stratiform cloud, but less so for broken clouds. On the other hand, $D_{\mathrm{i}}$ represents both cloud types well because it is calculated for individual cloud elements. Stratiform clouds are usually observed early in the morning, when the boundary layer is less coupled due to the smaller sensible heat flux. As the surface warms up, turbulence and therefore surfaceatmosphere coupling increases, and broken cumuli that have smaller $f_{\mathrm{c}}$ are formed.

The results presented here indicate that to first order, macroscopic variables such as cloud condensate and $f_{\mathrm{c}}$ rather than cloud microphysics are the properties that most determine the cloud radiative effect. Clearly the aerosol can play a role by modifying drop size and influencing how LWP manifests in $\tau_{\mathrm{c}}$ and $A_{\mathrm{c}}$. However, while LWP and $f_{\mathrm{c}}$ present a clear signature on rCRE, the aerosol signal is barely distinguishable. The aerosol signal is also difficult to quantify because of the uncertainty in calculation of the metrics derived from different methods (Table 2, Figs. 9d and 11d) and platforms (McComiskey and Feingold, 2012). Future studies that focus on understanding the role of dynamics and other meteorological drivers that potentially alter the macroscopic cloud properties will be reported on in the near future.

\section{Data availability}

The data used in this work can be accessed via the ARM Archive: http://www.archive.arm.gov/discovery/\#v/home/s/.

The Supplement related to this article is available online at doi:10.5194/acp-16-11301-2016-supplement.
Acknowledgements. The authors would like to thank the ARM (Atmospheric Radiation Measurement) Program for processing and providing the data sets used in this work. This work was supported by FAPESP grants 2014/04181-2 and 2013/08582-9, the US Department of Energy's Atmospheric System Research (ASR) program by grant DE-SC0014568 and by NOAA.

Edited by: J. Huang

Reviewed by: J. Quaas and one anonymous referee

\section{References}

Ackerman, A. S., Toon, O. B., Taylor, J. P., Johnson, D. W., Hobbs, P. V., and Ferek, R. J.: Effects of aerosols on cloud albedo: Evaluation of Twomey's parameterization of cloud susceptibility using measurements of ship tracks, J. Atmos. Sci., 57, 2684-2695, 2000.

Ackerman, A. S., Kirkpatrick, M. P., Stevens, D. E., and Toon, O. B.: The impact of humidity above stratiform clouds on indirect aerosol climate forcing, Nature, 432, 1014-1017, doi:10.1038/nature03174, 2004.

Albrecht, B. A.: Aerosols, cloud microphysics, and fractional cloudiness, Science, 245, 1227-1230, 1989.

Barnard, J. C. and Long, C. N.: A simple empirical equation to calculate cloud optical thickness using shortwave broadband measurements, J. Appl. Meteorol., 43, 1057-1066, 2004.

Barnard, J. C., Long, C. N., Kassianov, E. I., McFarlane, S. A., Comstock, J. M., Freer, M., and McFarquhar, G. M.: Development and evaluation of a simple algorithm to find cloud optical depth with emphasis on thin ice clouds, Open Atmos. Sci. J., 2, 46-55, 2008.

Betts, A. K. and Viterbo, P.: Land-surface, boundary layer, and cloud-field coupling over the southwestern Amazon in ERA40, J. Geophys. Res., 110, D14108, doi:10.1029/2004JD005702, 2005.

Boers, R. and Mitchell, R. M.: Absorption feedback in stratocumulus clouds influence on cloud top albedo, Tellus A, 46, 229-241, 1994.

Bohren, C. F.: Multiple scattering of light and some of its observable consequences, Am. J. Phys, 55.6, 524-533, 1987.

Boucher, O., Randall, D., Artaxo, P., Bretherton, C., Feingold, G., Forster, P., Kerminen, V.-M., Kondo, Y., Liao, H., Lohmann, U., Rasch, P., Satheesh, S. K., Sherwood, S., Stevens, B., and Zhang, X. Y.: Clouds and aerosols. in: Climate change 2013: the physical science basis - Contribution of Working Group I to the Fifth Assessment Report of the Intergovernmental Panel on Climate Change,Cambridge University Press, 571-657, 2013.

Bréon, F. M., Tanré, D., and Generoso, S.: Aerosol effect on cloud droplet size monitored from satellite, Science, 295, 834-838, 2002.

Chen, Y. C., Christensen, M. W., Stephens, G. L., and Seinfeld, J. H.: Satellite-based estimate of global aerosol-cloud radiative forcing by marine warm clouds, Nat. Geosci., 7, 643-646, 2014.

Chen, Y. C., Christensen, M. W., Diner, D. J., and Garay, M. J.: Aerosol-cloud interactions in ship tracks using Terra MODIS/MISR, J. Geophys. Res., 120, 2819-2833, 2015.

Clothiaux, E., Ackerman, T., Mace, G., Moran, K., Marchand, R., Miller, M., and Martner, B.: Objective deter- 
mination of cloud heights and radar reflectivities using a combination of active remote sensors at the arm cart sites, J. Appl. Meteor., 39, 645-665, doi:10.1175/15200450(2000)039<0645:ODOCHA>2.0.CO;2, 2000.

Costantino, L. and Bréon, F. M.: Analysis of aerosol-cloud interaction from multi-sensor satellite observations, Geophys. Res. Lett., 37, L11801, doi:10.1029/2009GL041828, 2010.

Delle Monache, L., Perry, K. D., Cederwall, R. T., and Ogren, J. A.: In situ aerosol profiles over the Southern Great Plains cloud and radiation test bed site: 2. Effects of mixing height on aerosol properties, J. Geophys. Res., 109, D06209, doi:10.1029/2003JD004024, 2004.

Eagan, R. C., Hobbs, P. V., and Radke, L. F.: Measurements of cloud condensation nuclei and cloud droplet size distributions in the vicinity of forest fires, J. Appl. Meteorol., 13, 553-557, 1974.

Engström, A. and Ekman, A. M.: Impact of meteorological factors on the correlation between aerosol optical depth and cloud fraction, Geophys. Res. Lett., 37, L18814, doi:10.1029/2010GL044361, 2010.

Feingold, G., Remer, L. A., Ramaprasad, J., and Kaufman, Y. J.: Analysis of smoke impact on clouds in Brazilian biomass burning regions: An extension of Twomey's approach, J. Geophys. Res., 106, 22907-22922, 2001.

Feingold, G., Eberhard, W. L., Veron, D. E., and Previdi, M.: "First measurements of the Twomey indirect effect using ground-based remote sensors", Geophys. Res. Lett., 30, 1287, doi:10.1029/2002GL016633, 2003.

Feingold, G., McComiskey, A., Yamaguchi, T., Johnson, J., Carslaw, K., and Schmidt, K. S.: New approaches to quantifying aerosol influence on the cloud radiative effect, Proc. Natl. Acad. Sci. USA, 113, 5812-5819, doi:10.1073/pnas.1514035112, 2016.

Frisch, A. S., Fairall, C. W., and Snider, J. B.: Measurement of stratus cloud and drizzle parameters in ASTEX with a K $\alpha$-band Doppler radar and a microwave radiometer, J. Atmos. Sci., 52, 2788-2799, 1995.

Garrett, T. J., Zhao, C., Dong, X., Mace, G. G., and Hobbs, P. V.: Effects of varying aerosol regimes on low-level Arctic stratus, Geophys. Res. Lett., 31, L17105, doi:10.1029/2004GL019928, 2004.

George, R. C. and Wood, R.: Subseasonal variability of low cloud radiative properties over the southeast Pacific Ocean, Atmos. Chem. Phys., 10, 4047-4063, doi:10.5194/acp-10-4047-2010, 2010.

Ghate, V. P., Miller, M. A., Albrecht, B. A., and Fairall, C. W.: Thermodynamic and Radiative Structure of Stratocumulus-Topped Boundary Layers, J. Atmos. Sci., 72, 430-451, 2015.

Han, Q., Rossow, W. B., Chou, J., and Welch, R. M.: Global survey of the relationships of cloud albedo and liquid water path with droplet size using ISCCP, J. Climate, 11, 1516-1528, 1998.

Huang, J., Fu, Q., Su, J., Tang, Q., Minnis, P., Hu, Y., Yi, Y., and Zhao, Q.: Taklimakan dust aerosol radiative heating derived from CALIPSO observations using the Fu-Liou radiation model with CERES constraints, Atmos. Chem. Phys., 9, 4011-4021, doi:10.5194/acp-9-4011-2009, 2009.

Kaufman, Y. J., Koren, I., Remer, L. A., Rosenfeld, D., and Rudich, Y.: The effect of smoke, dust, and pollution aerosol on shallow cloud development over the Atlantic Ocean, Proc. Natl. Acad. Sci. USA, 102, 11207-11212, 2005.
Kim, B. G., Schwartz, S. E., Miller, M. A., and Min, Q.: Effective radius of cloud droplets by ground-based remote sensing: Relationship to aerosol, J. Geophys. Res., 108, 4740, doi:10.1029/2003JD003721, 2003.

Kim, B. G., Miller, M. A., Schwartz, S. E., Liu, Y., and Min, Q.: The role of adiabaticity in the aerosol first indirect effect, J. Geophys. Res., 113, D05210, doi:10.1029/2007JD008961, 2008.

Klein, S. A. and Hartmann, D. L.: The seasonal cycle of low stratiform clouds, J. Climate, 6.8, 1587-1606, 1993.

Koren, I., Martins, J. V., Remer, L. A., and Afargan, H.: Smoke invigoration versus inhibition of clouds over the Amazon, Science, 321, p. 946, 2008.

Koren, I., Altaratz, O., Remer, L. A., Feingold, G., Martins, J. V., and Heiblum, R. H.: Aerosol-induced intensification of rain from the tropics to the mid-latitudes, Nat. Geosci., 5, 118-122, 2012.

Liu, Y., Wu, W., Jensen, M. P., and Toto, T.: Relationship between cloud radiative forcing, cloud fraction and cloud albedo, and new surface-based approach for determining cloud albedo, Atmos. Chem. Phys., 11, 7155-7170, doi:10.5194/acp-11-71552011, 2011.

Long, C. N. and Ackerman, T. P.: Identification of clear skies from broadband pyranometer measurements and calculation of downwelling shortwave cloud effects, J. Geophys. Res., 105, 1560915626, 2000.

Long, C. N. and Shi, Y.: The QCRad value added product: Surface radiation measurement quality control testing, including climatology configurable limits, Atmospheric Radiation Measurement Program Technical Report, 2006.

Long, C. N., Ackerman, T. P., Gaustad, K. L., and Cole, J. N. S.: Estimation of fractional sky cover from broadband shortwave radiometer measurements, J. Geophys. Res., 111, D11204, doi:10.1029/2005JD006475, 2006.

McComiskey, A. and Feingold, G.: The scale problem in quantifying aerosol indirect effects, Atmos. Chem. Phys., 12, 1031-1049, doi:10.5194/acp-12-1031-2012, 2012.

McComiskey, A, Feingold, G., Frisch, A. S., Turner, D. D., Miller, M., Chiu, J. C., Min, Q., and Ogren, J.: An assessment of aerosol-cloud interactions in marine stratus clouds based on surface remote sensing, J. Geophys. Res., 114, D09203, doi:10.1029/2008JD011006, 2009.

Min, Q. and Harrison, L. C.: Cloud properties derived from surface MFRSR measurements and comparison with GOES results at the ARM SGP site, Geophys. Res. Lett., 23, 1641-1644, 1996.

Nakajima, T., Higurashi, A., Kawamoto, K., and Penner, J. E.: A possible correlation between satellite-derived cloud and aerosol microphysical parameters, Geophys. Res. Lett., 28, 1171-1174, 2001.

Platnick, S. and Twomey, S.: Determining the susceptibility of cloud albedo to changes in droplet concentration with the Advanced Very High Resolution Radiometer, J. Appl. Meteorol., 33, 334-347, 1994.

Quaas, J., Boucher, O., Bellouin, N., and Kinne, S.: Satellite-based estimate of the direct and indirect aerosol climate forcing, J. Geophys. Res., 113, D05204, doi:10.1029/2007JD008962, 2008.

Sheridan, P. J., Delene, D. J., and Ogren, J. A.: Four years of continuous surface aerosol measurments from the Department of Energy's Atmospheric Radiation Measurement Program Southern Great Plains Cloud and Radiation Testbed site, J. Geophys. Res., 106, 20735-20747, 2001. 
Small, J. D., Chuang, P. Y., Feingold, G., and Jiang, H.: Can aerosol decrease cloud lifetime?, Geophys. Res. Lett., 36, L16806, doi:10.1029/2009GL038888, 2009.

Stephens, G. L., Paltridge, G. W., and Platt, C. M. R.: Radiation profiles in extended water clouds - III: Observations, J. Atmos. Sci., 35, 2133-2141, 1978.

Stevens, B. and Feingold, G.: Untangling aerosol effects on clouds and precipitation in a buffered system, Nature, 461, 607-613, 2009.

Trenberth, K. E., Fasullo, J. T., and Kiehl, J.: Earth's global energy budget, B. Am. Meteorol. Soc., 90, 311-323, 2009.

Troyan, D.: Merged Sonding Value-Added Product Technical Report, US Department of Energy, DOE/SC-ARM-TR-087, 2012.

Turner, D. and Min, Q.: Cloud Optical Properties from the MultiFilter Shadowband Radiometer (MFRSRCLDOD): An ARM Value-Added Product Technical Report US, Department of Energy, DOE/SC-ARM-TR-047, 2004.

Turner, D. D., Clough, S. A., Liljegren, J. C., Clothiaux, E. E., Cady-Pereira, K., and Gaustad, K. L.: Retrieving liquid water path and precipitable water vapor from Atmospheric Radiation Measurement (ARM) microwave radiometers, IEEE Trans. Geosci. Remote Sens., 45, 3680-3690, doi:10.1109/TGRS.2007.903703, 2007a.

Turner, D. D., Vogelmann, A. M., Austin, R. T., Barnard, J. C., Cady-Pereira, K., Chiu, J. C., Clough, S. A., Flynn, C., Khaiyer, M. M., Liljegren, J., and Johnson, K.: Thin liquid water clouds: Their importance and our challenge, B. Am. Meteorol. Soc., 88, 177-190, 2007b.

Twohy, C. H., Petters, M. D., Snider, J. R., Stevens, B., Tahnk, W., Wetzel, M., Russell, L., and Burnet, F.: Evaluation of the aerosol indirect effect in marine stratocumulus clouds: Droplet number, size, liquid water path, and radiative impact, J. Geophys. Res., 110, D08203, doi:10.1029/2004JD005116, 2005.

Twomey, S.: The nuclei of natural cloud formation part II: The supersaturation in natural clouds and the variation of cloud droplet concentration, Geofisica pura e applicata, 43, 243-249, 1959.
Twomey, S.: Pollution and the planetary albedo, Atmos. Environ., 8, 1251-1256, 1974.

Twomey, S.: The influence of pollution on the shortwave albedo of clouds, J. Atmos. Sci., 34, 1149-1152, 1977.

Vavrus, S.: An alternative method to calculate cloud radiative forcing: Implications for quantifying cloud feedbacks, Geophys. Res. Lett., 33, L01805, doi:10.1029/2005GL024723, 2006.

Vogelmann, A. M., McFarquhar, G. M., Ogren, J. A., Turner, D. D., Comstock, J. M., Feingold, G., Long, C. N., Jonsson, H. H., Bucholtz, A., Collins, D. R., and Diskin, G. S.: RACORO extendedterm aircraft observations of boundary layer clouds, B. Am. Meteorol. Soc., 93, 861-878, 2012.

Wang, S., Wang, Q., and Feingold, G.: Turbulence, condensation and liquid water transport in numerically simulated nonprecipitating stratocumulus clouds, J. Atmos. Sci., 60, 262-278, doi:10.1175/1520-0469(2003)060<0262:TCALWT>2.0.CO;2, 2003.

Warner, J. and Twomey, S.: The production of cloud nuclei by cane fires and the effect on cloud droplet concentration, J. Atmos. Sci., 24, 704-706, 1967.

Wen, G., Marshak, A., Cahalan, R. F., Remer, L. A., and Kleidman, R. G.: 3-D aerosol-cloud radiative interaction observed in collocated MODIS and ASTER images of cumulus cloud fields, J. Geophys. Res., 112, D13204, doi:10.1029/2006JD008267, 2007.

Wood, R. and Bretherton, C. S.: On the relationship between stratiform low cloud cover and lower-tropospheric stability, J. Climate, 19, 6425-6432, 2006.

Xie, Y. and Liu, Y.: A new approach for simultaneously retrieving cloud albedo and cloud fraction from surface-based shortwave radiation measurements, Environ. Res. Lett., 8, 044023 , doi:10.1088/1748-9326/8/4/044023, 2013. 